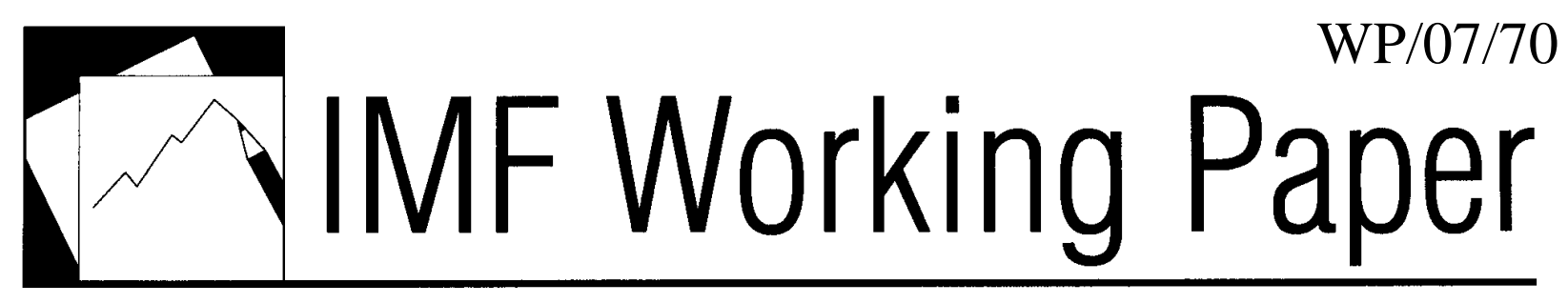

\title{
Modeling Aggregate Use of Fund Resources-Analytical Approaches and Medium-Term Projections
}

Atish Ghosh, Manuela Goretti, Bikas Joshi, Alun Thomas, and Juan Zalduendo 



\title{
IMF Working Paper
}

Policy Development and Review Department

\section{Modeling Aggregate Use of Fund Resources- Analytical Approaches and Medium-Term Projections}

\section{Prepared by Atish Ghosh, Manuela Goretti, Bikas Joshi, Alun Thomas, and Juan Zalduendo ${ }^{1}$}

Authorized for distribution by Mark Allen

March 2007

\begin{abstract}
This Working Paper should not be reported as representing the views of the IMF. The views expressed in this Working Paper are those of the author(s) and do not necessarily represent those of the IMF or IMF policy. Working Papers describe research in progress by the author(s) and are published to elicit comments and to further debate.

This paper presents two approaches to modeling the use of IMF resources in order to gauge whether the recent decline in credit outstanding is a temporary or a permanent phenomenon. The two approaches - the time series behavior of credit outstanding and a two-stage program selection and access model-yield the same conclusion: the use of IMF resources is likely to decline sharply. Specifically, credit outstanding is projected to decline from an average of SDR 50 billion over $2000-05$ to SDR 8 billion over 2006-10. Stochastic simulations suggest that it is unlikely to be much higher. These results are based on WEO projections with a correction for historically-observed over-optimistic biases. Alternative scenarios assuming a weaker economic performance or a less benign global environment do not alter these results.
\end{abstract}

JEL Classification Numbers: F01, F33, F34, F42

Keywords: Stand-by arrangements, prediction, IMF lending capacity, IMF income position Author's E-Mail Address: aghosh@imf.org, mgoretti@imf.org, bjoshi@imf.org, athomas@imf.org,jzalduendo@imf.org

\footnotetext{
${ }^{1}$ We would like to thank Mark Allen, Jorge Márquez-Ruarte, Russell Kincaid, Jonathan Ostry, Gary Schinasi, Jim Boughton, Andy Berg, and other IMF colleagues for useful discussions and suggestions during the preparation of this paper, and Sibabrata Das for research assistance. The literature survey (Appendix II) is an abbreviated version of a survey prepared by Patricia Brukoff, Julie Kozack, Alex Pitt, and Björn Rother.
} 


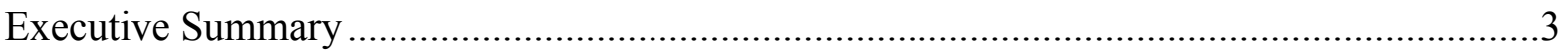

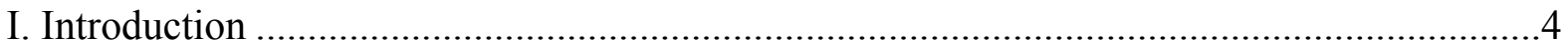

II. Aggregate Use of IMF Resources — Current and Historical Trends .....................................7

III. Time Series Model of Aggregate UFR …………….......................................................10

IV. Modeling Individual Members' Use of IMF Resources ..................................................17

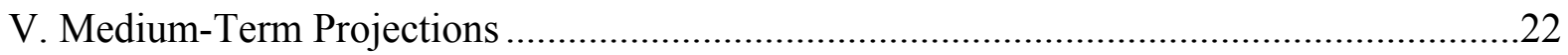

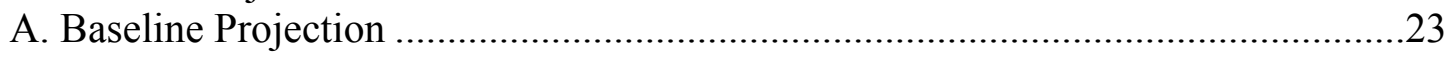

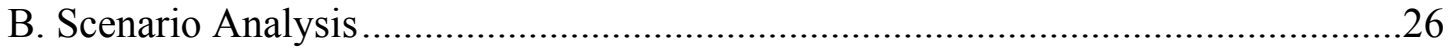

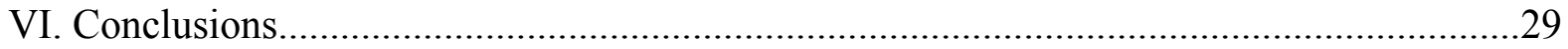

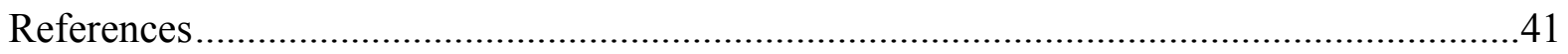

Appendix I. Is There Evidence of a Nonlinear Process in the Demand for Use of Fund Resources ............................................................................................

Appendix II. Demand for IMF Resources - Literature Survey ................................................34

Appendix Table 1. Determinants of Use of IMF Resources Under Switching Regimes .........31

Appendix Table 2. Literature on Determinants of Demand for IMF Resources ......................37

Tables

1. Determinants of Changes in Fund Credit Outstanding (1980-2005) .................................15

2. Selection Stage: Decision to Request an SBA/EFF ……..............................................19

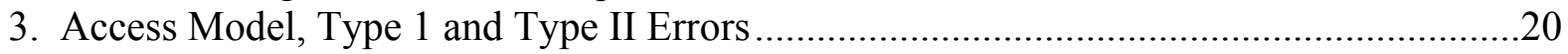

4. Access Stage: Determinants of Access Levels in an SBA/EFF......................................21

Figures

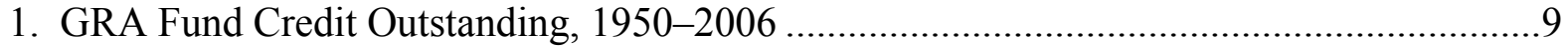

2. GRA Fund Credit Outstanding: Middle Income Country Sample, 1970-2006...................11

3. GRA Fund Credit Outstanding: Number, Concentration, and Trends.................................12

4. Fund Credit Outstanding: Actual and Fit of Time-series Model ........................................16

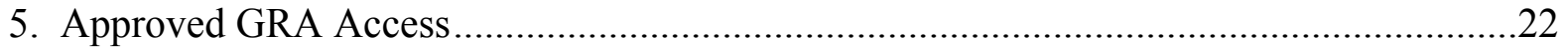

6. Medium-term Projections of Fund Credit Outstanding ...................................................24

7. Stochastic Simulation of Outstanding Fund Credit (2006- 10; GRA only)........................27

8. Alternative Scenarios of Fund Credit Outstanding ............................................................28 


\section{EXECUTIVE SUMMARY}

The recent decline in outstanding IMF resources raises the question of whether this is a temporary phenomenon resulting from a benign global environment or a more fundamental shift due to improved macroeconomic performance and increased resiliency to shocks among key IMF member countries. This paper attempts to answer this question by modeling aggregate use of Fund resources (UFR) for middle-income countries. Doing so poses analytical challenges as IMF lending is unique: demand for UFR is determined by balance of payment difficulties, supply depends on the institution's policies and on the willingness of national authorities to adopt an economic program that the IMF can support, and the rate of charge is not adjusted to equilibrate supply and demand. Moreover, to be useful for mediumterm projections, any model employed needs to be parsimonious since the explanatory variables must themselves be forecastable.

Given these challenges, this paper adopts two distinct analytical approaches. The first approach considers the time-series behavior of aggregate UFR. This has the advantage of modeling the variable-IMF credit outstanding - that is of direct relevance for IMF income and liquidity. The second approach models individual members' use of the IMF's resources by first using a discrete choice model to determine the likelihood that a member will have an IMF-supported program, then using regression analysis to predict the level of access, and finally calculating credit outstanding by assuming disbursement and repayment profiles.

The difficulties inherent in forecasting use of IMF resources mean that any projections will be subject to a significant degree of uncertainty. Moreover, they will be only as good as the projections for the explanatory variables. With these caveats in mind, the main results are:

- The time series analysis suggests that there is a long-run, positive relationship between aggregate use of IMF resources and countries' total external debt, short-term external debt, and IMF quota. In addition, the short-run dynamics depend on the change in the current account balance and on the imports coverage of reserves.

- The two-stage "program selection and access" model finds that a member is more likely to have an IMF arrangement the lower its reserve cover, the higher its external debt and its external and fiscal adjustment, the higher the price of oil for oil importers (and the lower the price of oil for oil exporters), and the higher its inflation rate. Controlling for program selection, access to IMF resources is larger the higher the member's external debt and the greater its external adjustment.

- The time series analysis and the "program selection and access" models yield similar projections of aggregate use of IMF resources; based on current WEO projections, both models predict that aggregate UFR will average about SDR 8 billion over the period 2006-2010 compared to an average of SDR 50 billion over the past few years.

- Plausible alternative scenarios - correcting for (historically-observed) biases in WEO forecasts or considering weaker macroeconomic perfomance or a less benign global environment - do not materially alter these results. 


\section{INTRODUCTION}

The recent decline in outstanding IMF resources raises the question of whether this is a temporary phenomenon - perhaps reflecting an exceptionally benign global environment — or a more fundamental shift in the use of IMF's General Resources due to improved macroeconomic performance and increased resiliency to shocks among many middle-income countries. As previous researchers have found, modeling aggregate UFR and projecting its future demand poses analytical challenges because the nature of IMF lending is unique: ${ }^{2}$ demand for UFR is determined by balance of payments difficulties, supply of IMF resources depends on the institution's policies (for instance, on exceptional access) and on the willingness of national authorities to adopt an economic program that the IMF can support, and the rate of charge is not adjusted to equilibrate supply and demand of IMF resources.

A further complication in modeling IMF credit outstanding (which forms the institution's income base) is that this portfolio has become increasingly concentrated over the years-both because the pool of members that might draw General Resource Account (GRA) resources has shrunk (as advanced economies "graduated" from IMF support and low-income countries switched to drawing concessional resources instead) and because exceptional access cases have come to dominate the portfolio. ${ }^{3}$ This portfolio concentration means that aggregate UFR depends on shocks that affect just a few members' balance of payments needs (and the precise timing of those needs) rather than on a "law of large numbers" averaging of idiosyncratic shocks across many members. Relatedly, the very large capital account crisis programs are especially difficult to handle econometrically because there are only 16 such cases (in a sample of 236 GRA arrangements over the period 1972-2005) - though they account for a large portion of IMF credit outstanding over the past decade. In addition, any proposed model specification needs to be parsimonious since the explanatory variables must themselves be forecastable in order to project aggregate use of IMF resources.

Given these challenges, this paper adopts two distinct analytical approaches to modeling the outstanding stock of IMF credit. The first considers the behavior of aggregate UFR directly. This has the advantage of modeling the variable - aggregate IMF credit outstanding - that is of direct relevance for IMF income and liquidity. By focusing on aggregate net credit outstanding, the approach captures implicitly gross purchases and repurchases - obviating the need to model these separately_-but requiring the assumption of a stable process for members' patterns of purchases and repurchases. While repurchases must be made no later than the date required by the obligations schedule, in a number of recent cases the member

\footnotetext{
${ }^{2}$ Appendix II reviews previous studies of use of IMF credit. Worth noting is the study by Elekdağ (2006), on which the second approach developed here draws in modeling the decision to have an IMF-supported program; the second approach discussed in this paper builds on the analysis of Joshi and Zalduendo (2006). Other recent work includes Cerutti (2007).

${ }^{3}$ Whereas during the 1980s the three largest arrangements accounted for about one-quarter of the portfolio and the ten largest for around one-half of the portfolio, the corresponding proportions for the period 1995-2005 were, respectively, more than one-half and three-quarters of the portfolio.
} 
has chosen to make repurchases ahead of schedule, while in other cases-where the member faced a continuing balance of payments need - a new arrangement allowed it to keep its IMF credit outstanding roughly constant while making scheduled repurchases. Moreover, changes in certain IMF policies in the past few years, including on charges, expectation-based repurchases, and post-program monitoring are likely to have had an impact on members' repurchase behavior. Finally, as the number of potential GRA-drawing members has shrunk, but average access has increased, aggregate UFR may be a relatively more stable time series than individual members' use of IMF resources.

Underlying this approach is a model of the world in which there is a large pool of (relatively homogenous) potential GRA users that are subject to idiosyncratic shocks. Thus, when one member is experiencing balance of payments problems requiring IMF support, others are likely to be recovering from their balance of payments difficulties, rendering the aggregate portfolio both fairly stable and largely determined by the average economic performance of the group of countries (as well as global factors). While this was probably the case in earlier years, when limited private capital flows meant that contagion was less likely and the potential GRA users included almost the whole membership, the trend toward fewer - and in some cases, financially larger_-programs makes this model potentially less applicable.

The time series analysis of aggregate UFR is therefore complemented by a more "bottomsup" approach that models individual members' use of IMF resources and then aggregates across the membership. ${ }^{4}$ Specifically, a discrete choice model (using a logit specification) is used to determine the likelihood that a member will have a IMF-supported program, with stochastic simulations used to generate the probability density function of programs across the relevant membership. Regression analysis is then used to predict the level of access conditional on program approval, and the predicted access is then aggregated across the membership. Finally, the probability density function of aggregate approved access is translated into IMF credit outstanding by assuming a disbursement and repayment schedule. ${ }^{5}$

While this "program selection and access" model does not depend on the assumption that GRA users consist of a large pool of relatively homogenous countries, it does require the ability to predict the likelihood that an individual member will face a balance of payments problem - and the extent of that problem. Experience with "early warning models"-which only seek to model the likelihood of a crisis - suggests that this is a tall order. Moreover, since this approach is based on modeling individual members' use of IMF resources, it does

\footnotetext{
${ }^{4}$ Since this paper seeks to project likely use of GRA resources over the medium term, the aggregation is restricted to members that have had at least one GRA arrangement since 1972, excluding current advanced economies and PRGF-eligible countries. Over the longer term, demand for GRA resources may come from current low-income countries that "graduate" from PRGF eligibility (and possibly middle-income countries that have not had an arrangement since 1970), but this is not considered here.

${ }^{5}$ Disbursement ratios (amount disbursed as a fraction of original approved access) are typically less than one hundred percent, either because the Fund-supported program goes off-track or because members treat the arrangement as precautionary. Conversely, in some cases, the disbursement ratio exceeds unity because access is augmented after the original program is approved. Empirically, as later discussed, the aggregate disbursement ratio is around $75-80$ percent.
} 
not take advantage of any averaging out of prediction errors across the membership — nor of the (partially) offsetting trends of fewer, but larger programs.

A further caveat is that both the time series and program selection and access models should be considered reduced-form estimates of the joint decision of national authorities to request the IMF's financial support of their economic program, and of the IMF to provide that support. Ideally, these would be modeled separately, with their conjuncture determining the equilibrium outcome of a IMF-supported program (with associated access). In practice, however, it is hard to find convincing identifying restrictions and - as discussed belowsimply imposing such restrictions leads to convergence problems in the estimation and to unstable parameter estimates. ${ }^{6}$ Moreover, while desirable, identifying separate demand and supply functions for UFR is less critical here, as the main purpose of the models is to project use of IMF resources that reflects the equilibrium outcome of demand and supply given forecasts of explanatory variables that might affect both. ${ }^{7}$

The difficulties inherent in forecasting aggregate use of IMF resources - and the limitations of either approach - mean that any projections of UFR will necessarily be subject to a significant degree of uncertainty. Moreover, they will be only as good as the projections for the explanatory variables in the regressions. These are mainly based on country teams' WEO (October 2006) projections which, however, have been shown in previous studies to be subject to some optimistic biases, in particular as the forecast horizon lengthens. ${ }^{8}$ Bearing these caveats in mind, the main findings may be summarized as follows.

- Time series analysis suggests that there is a long-run positive relationship between aggregate UFR and middle-income countries' external debt (in percent of GDP), short-term debt (in percent of reserves), and IMF quota (or trade openness, in percent of GDP). Short-run dynamics around this long-run relationship depend on the change in the current account balance and on the imports coverage of reserves. The fit of the model is generally good, explaining 70 percent of the variation in IMF credit outstanding.

\footnotetext{
${ }^{6}$ Only Przeworski and Vreeland (2000) estimate separate "demand" and "supply" equations for Fund-supported programs but impose implausible assumptions that a member's balance of payments deficit or political regime do not influence its decision to seek Fund support—but that these variables enter the Fund's decision on whether to provide such support. Conversely, the member's decision to seek Fund support depends upon its level of reserves, its budget deficit, and its debt service - variables that are assumed not to enter the Fund's decision. It is possible to estimate the program selection and access model without imposing identifying restrictions. However, as Maddala (1983, p. 282) notes, doing so typically does not produce good parameter estimates. Nonetheless, as a robustness check, the results of such a partially observed bivariate probit estimation is discussed elsewhere in this paper.

${ }^{7}$ By analogy, to know the effect of an increase in the price of apples on the demand for, and supply of, apples requires estimating demand and supply functions. But to know the effect of an increase in income-which may affect demand or supply (or both) — only a reduced form model is required.

${ }^{8}$ See Joshi and Ghosh (2003), Ghosh et al. (2005), and IMF (2005a).
} 
- The two-stage "program selection and access" model finds that a member is more likely to have a IMF-supported program the higher its external debt, the lower its reserves coverage of imports, the greater its external and fiscal adjustment, the higher the price of oil for oil importers (the lower the price of oil, for oil exporters), and the higher its inflation rate. In 73 percent of cases where the member had a program, the estimated probability is above the threshold probability implied by the sample frequency of programs; in 67 percent of cases where the member did not have a program, the estimated probability is below the threshold.

- Controlling for the factors that determine participation in an IMF-supported program, access to IMF resources is larger the higher the country's external debt and the greater its external adjustment. Access is also higher for systemically large countries with high external debt (proxied by countries in top deciles of the sample in terms of the U.S. dollar value of GDP and an external debt ratio above 40 percent of GDP).

- $\quad$ The time series analysis and the program selection and access model yield similar projections of aggregate use of IMF resources for the next five years. Specifically, based on current World Economic Outlook (WEO) projections for the main explanatory variables, both models predict an average of about SDR 8 billion. By comparison, over the period 2000-05, outstanding credit averaged SDR 50 billion.

- A less benign scenario for the macroeconomic performance of potential GRA users (in particular, applying a correction for biases observed in previous WEO projections), yields aggregate IMF credit outstanding for the next five years that is about SDR 1 billion higher than in the above baseline forecast.

The remainder of this paper is organized as follows. Section II puts current trends of the demand for UFR in historical context. Section III develops a model of aggregate UFR. Section IV turns to the disaggregated approach, developing first a discrete choice model of when a member is likely to request IMF support and then a panel, generalized least-squares regression model of expected access conditional on such a request. Section V draws the implications of both approaches for the likely aggregate use of IMF resources over the medium-term. Section VI concludes.

\section{Aggregate USE of IMF ResourCes-Current And Historical Trends}

Aggregate use of IMF credit has varied widely in the past, and the recent downturn is certainly not the first time there has been a nominal and real (deflated by the CPIs of the SDR constituent countries) decline in aggregate UFR (Figure 1). For the first few years after the IMF opened its doors in 1947, there was very limited use of IMF credit (i.e., drawings beyond members' gold tranche) — and hence little income - because most developing countries had emerged from the World War II commodity boom with substantial foreign 
exchange reserves, while European countries that had access to Marshall Plan funds were discouraged from drawing IMF resources. ${ }^{9}$

Aggregate UFR picked up during the 1960s, as countries experienced balance of payments difficulties and the Bretton Woods system came increasingly under strain. The collapse of Bretton Woods itself - together with the move to floating exchange rates by the industrialized countries - reduced the demand for use of IMF resources; however, the number of arrangements and IMF credit outstanding soon picked up again in the aftermath of the 1973 and 1979 oil shocks. The number of arrangements in place peaked during the debt crisis in the first half of the 1980s (Figure 1, bottom panel), with IMF credit outstanding reaching some SDR 50 billion, but this had almost halved to SDR 26 billion by 1989 as these countries emerged from the debt crisis and private capital flows resumed in the early 1990s.

Demand for UFR increased anew in the first half of the 1990s when the IMF became involved in helping members transition from centrally planned to market economies, followed by a series of exceptionally large programs to deal with capital account crisesbeginning with Mexico in 1995 and including the Asian crisis countries, Argentina, Brazil, and Turkey. In real SDR terms, aggregate use of IMF resources peaked in 1998 at SDR 62 billion, falling to SDR 43 billion in 2000, increasing to almost SDR 62 billion in 2003 before plummeting to less than SDR 30 billion in 2005 owing to early repurchases. Additional early repurchases during 2006 have brought down further the level of outstanding IMF resources to about SDR 11 billion as of end 2006.

Included in this long time series of UFR are arrangements with advanced economies and low-income countries. But advanced economies have not tapped IMF resources since the early 1980s, while low-income countries typically access concessional (non-GRA) resources. ${ }^{10}$ For the purposes of projecting future use of GRA resources, therefore, it is useful to focus on middle-income countries - more precisely, a sample of "potential GRA users" which is defined here as members that have had at least one GRA arrangement (including first credit tranche arrangements) since 1972 but excluding current advanced economies and current PRGF-eligible countries. ${ }^{11}$

\footnotetext{
${ }^{9}$ Indeed, by end FY-1951, the Fund had a cumulative net deficit of US\$7.2 million — which "caused some anxiety in the Board, and influenced its decisions on such matters as the size of the staff and the amount of traveling that was undertaken" (Horsefield, 1969, p. 304).

${ }^{10}$ These include the Structural Adjustment Facility (SAF), Extended Structural Adjustment Facility (ESAF), and, more recently, the Poverty Reduction and Growth Facility (PRGF).

${ }^{11}$ Other than Bolivia, India, Papua New Guinea and Nigeria; PRGF-eligible countries that have accessed GRA resources since 1990 (excluding blended arrangements). Although the sample of middle-income countries in the World Development Indicators is much larger (about 90 countries instead of the 53 covered in this paper), the difference reflects mostly small economies that would have only a marginal effect on aggregate UFR; in fact, the countries in this paper account for about 90 percent of the IMF quota of middle-income countries.
} 
Figure 1. GRA Fund Credit Outstanding, 1950-2006 1/

Nominal and Real Fund Credit Outstanding, in billions of SDRs

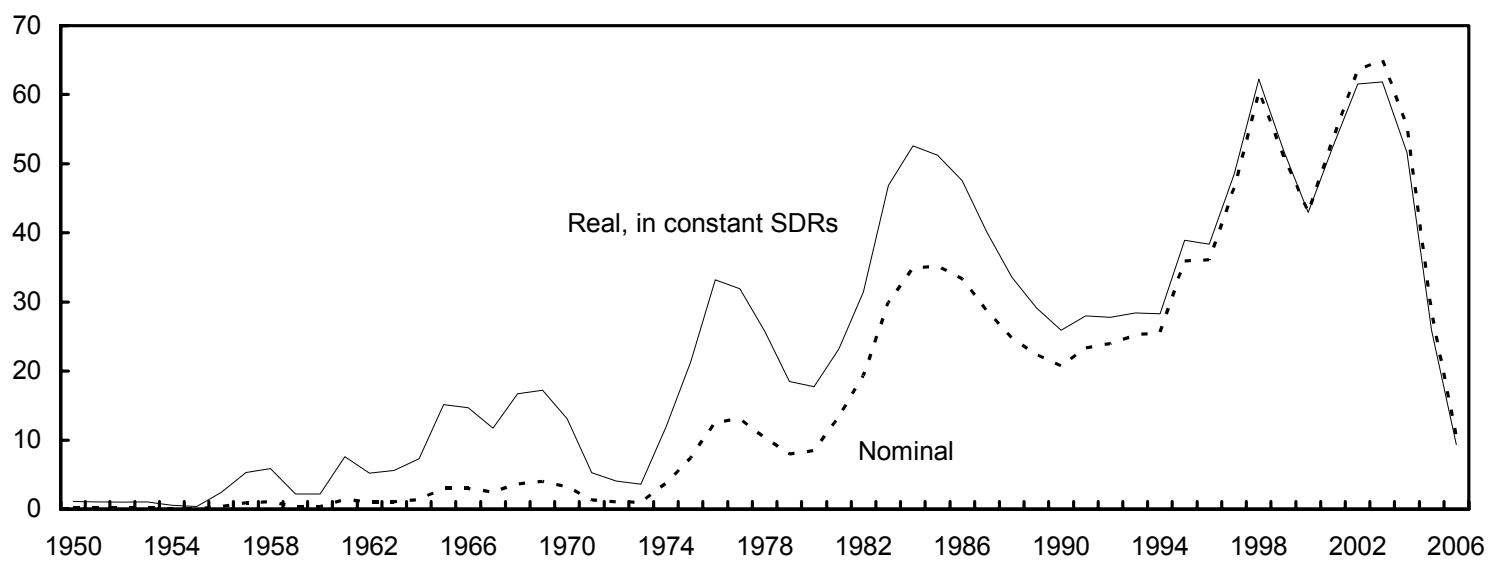

Fund Credit Outstanding, in millions of constant SDRs (logarithmic scale)

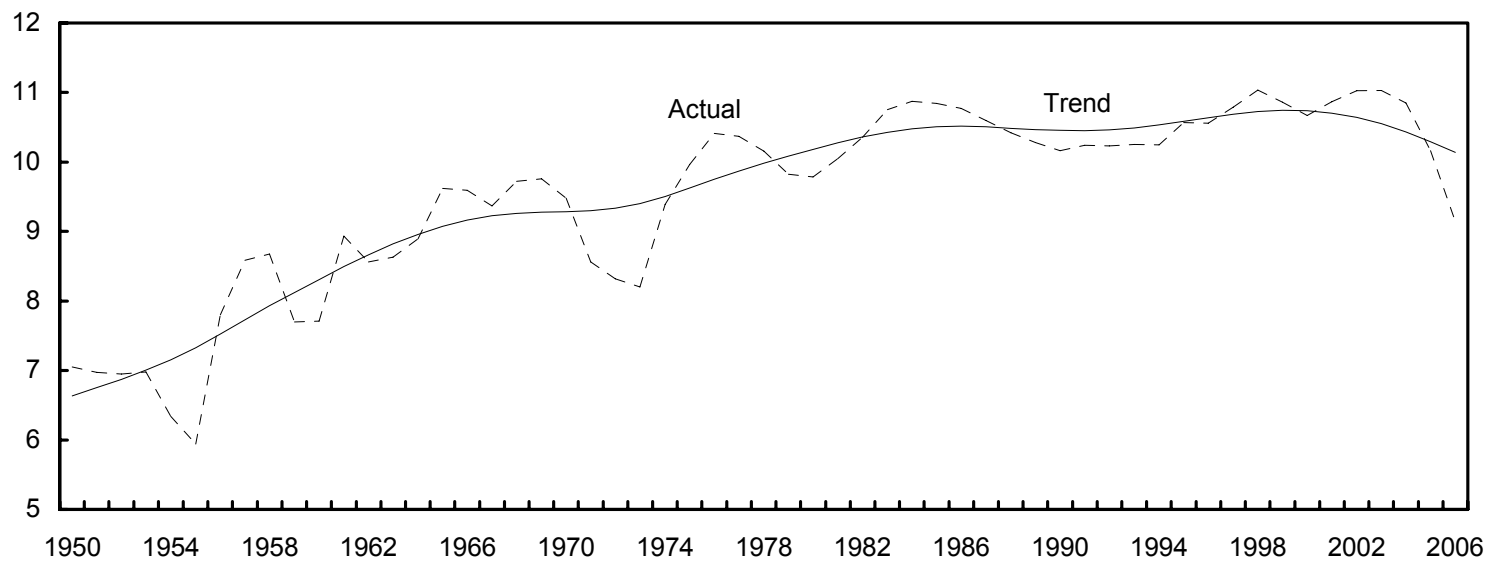

Number of GRA Arrangements in Place

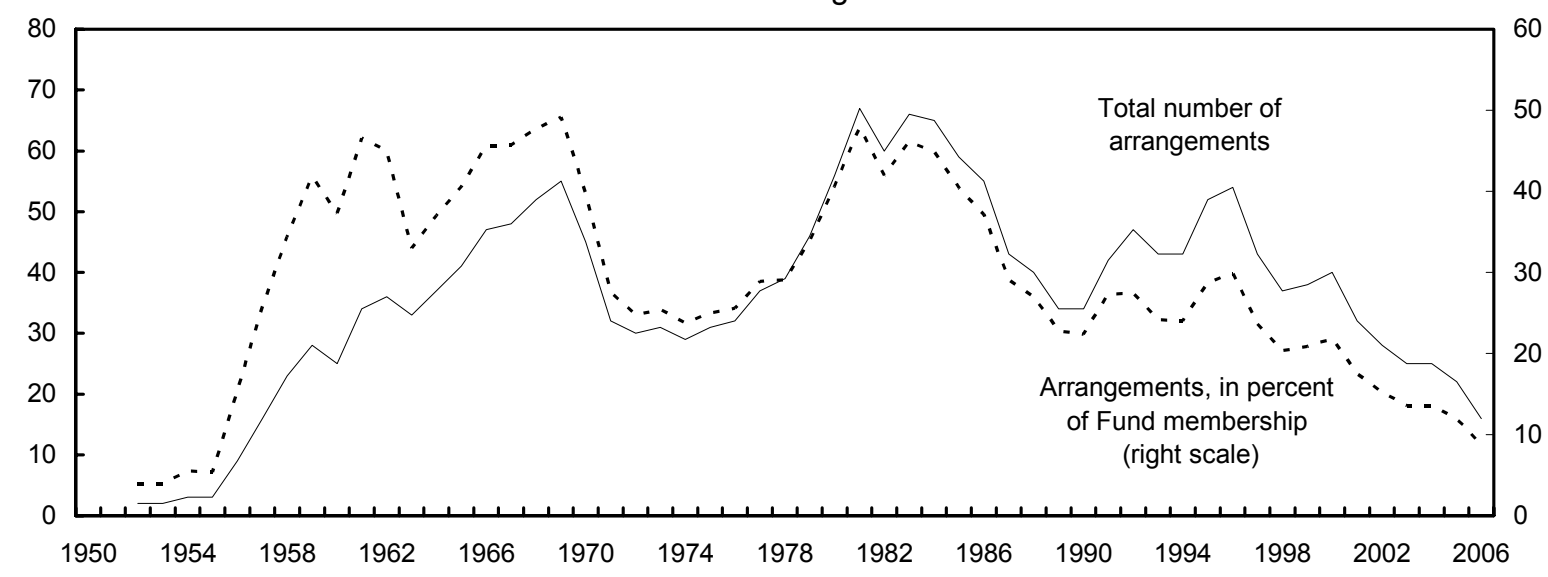

Sources: International Monetary Fund, IFS database; and staff estimates.

1/ 2006 data as of November 2006. 
While this sample captures most members that might plausibly request use of GRA resources over the next five years, it does not take account of low-income countries that, over the longer-term, are likely to improve their financial situation allowing them to access nonconcessional IMF support if they run into balance of payments difficulties. Conversely, the sample of "potential GRA users" includes countries that are unlikely to turn to the IMF even in a crisis. In some cases, this has been manifested in improved economic performance and greater resiliency to shocks, for instance by building up large, precautionary holdings of foreign exchange reserves; in the econometric analysis below, the model would (correctly) predict that such members are unlikely to use IMF resources. But in other cases, a desire to avoid future IMF support may not be matched by corresponding policies or resiliency to shocks: the econometric models would predict programs for these countries, though it is difficult to know how the balance would tilt.

Although use of IMF credit by this group of "potential GRA-users" rose sharply beginning in the mid-1990s, much of the increase reflected a few exceptional access arrangements (Figure 2). Indeed, the number of GRA arrangements both in absolute terms and in proportion to the number of IMF members in this group has been declining almost monotonically since the mid-1990s (Figure 2; bottom panel). As a result, and because of a greater prevalence of arrangements that authorities treat as precautionary, ${ }^{12}$ the concentration of the GRA portfolio has increased considerably, with the three largest arrangements accounting for more than 60 percent of the portfolio and the five largest for 75 percent (Figure 3; top panel). The small number of members drawing IMF resources (at any point in time) and the portfolio concentration, in turn, mean that projections of use of IMF resources cannot take (much) advantage of a "law of large numbers" averaging of idiosyncratic shocks across members that would make the aggregate portfolio stable.

Some of the difficulties in projecting future use of IMF credit are evident from the bottom panel of Figure 3, which considers alternative extrapolations of the time series trend of aggregate UFR. Seemingly plausible methods of extrapolation-for instance, based on the average growth rate of the sample, or the average growth rate of the trend - can lead to very different projections. Therefore, economics-based models are developed below.

\section{Time Series Model OF Aggregate UFR}

One approach to modeling UFR is to consider the time series behavior of the aggregate stock of outstanding IMF credit (to the group of "potential GRA-users," as defined above). ${ }^{13}$ This has the advantage of modeling the variable that is of direct relevance to IMF income, and of not requiring projections of individual members' IMF drawings or repurchases. Standard time series techniques can be applied to obtain long-run (cointegrating) relationships between

\footnotetext{
${ }^{12}$ See IMF, 2006.

${ }^{13}$ Since the dependent variable is Fund GRA credit outstanding (to the group of "potential GRA-users") it does not include amounts approved but not drawn (including resources that would be available under a precautionary arrangement).
} 
Figure 2. GRA Fund Credit Outstanding: Middle Income Country Sample, 1970-2006 1/

Fund Credit Outstanding, in constant SDRs (logarithmic scale)

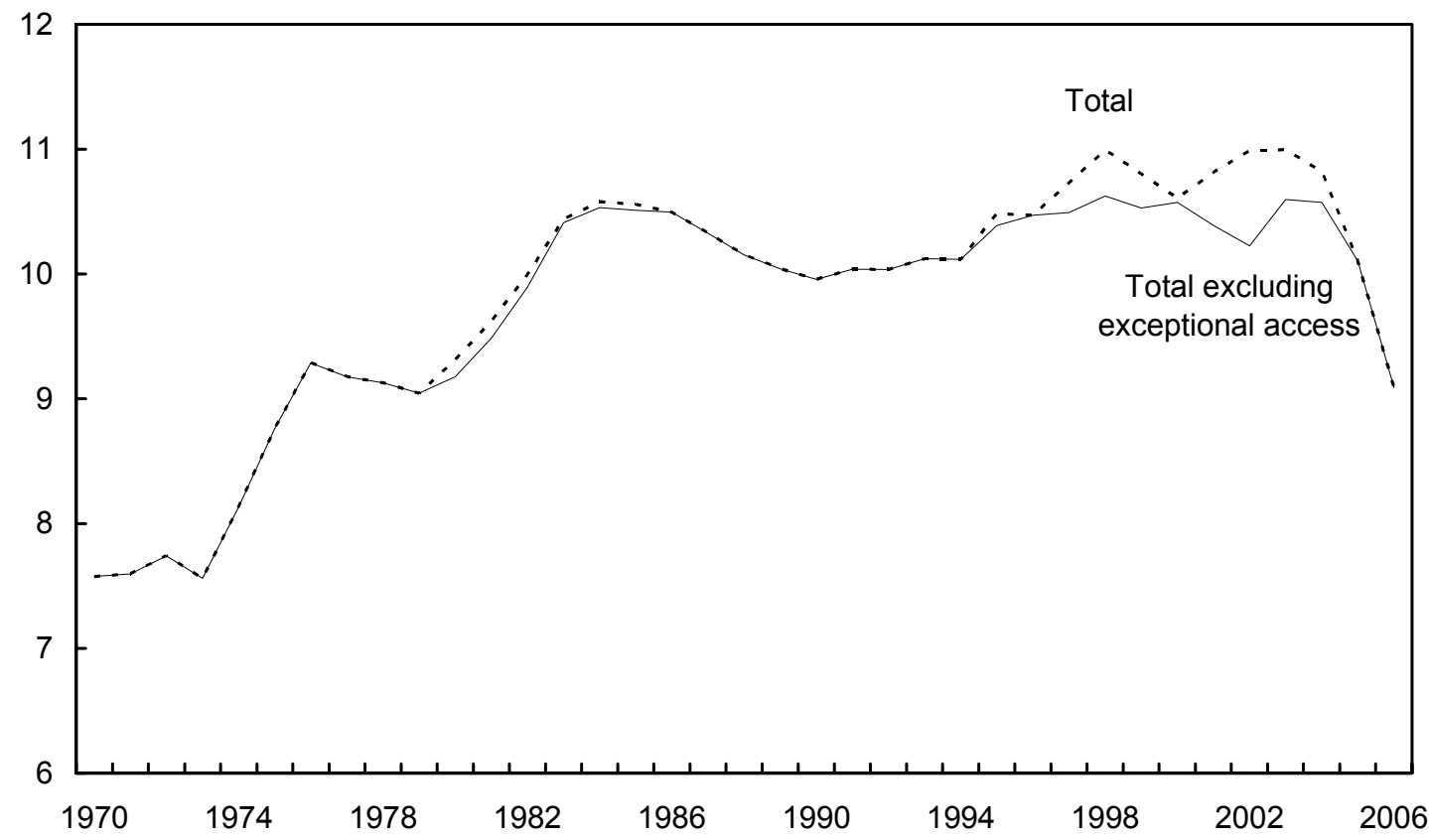

Number of GRA Arrangements in Place

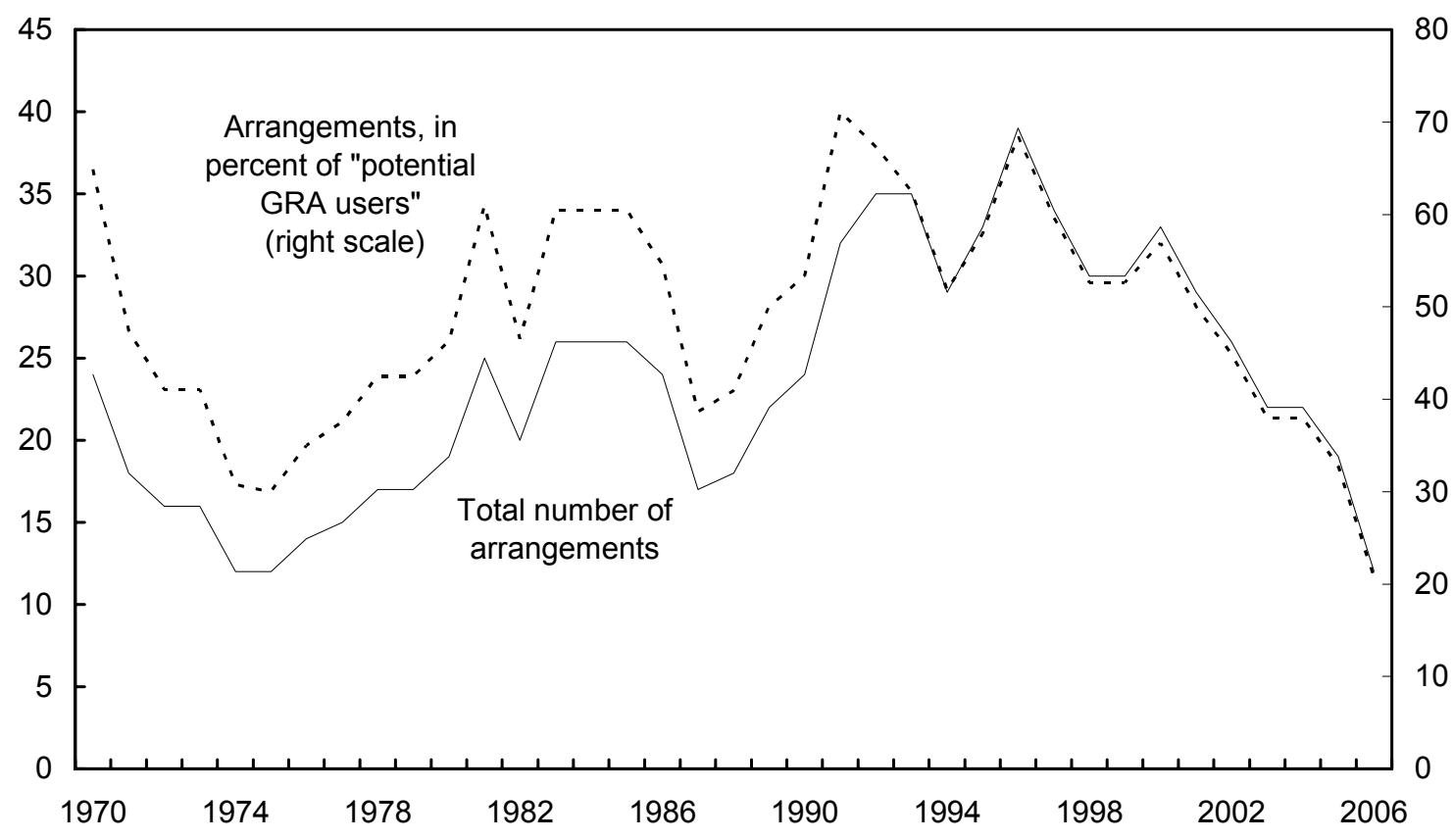

Sources: International Monetary Fund, IFS database; and staff estimates.

1/ 2006 data as of November 2006. 
Figure 3. GRA Fund Credit Outstanding: Number, Concentration, and Trends

\section{Concentration Ratios of Fund Credit in Top 3 Arrangements}

(In percent)

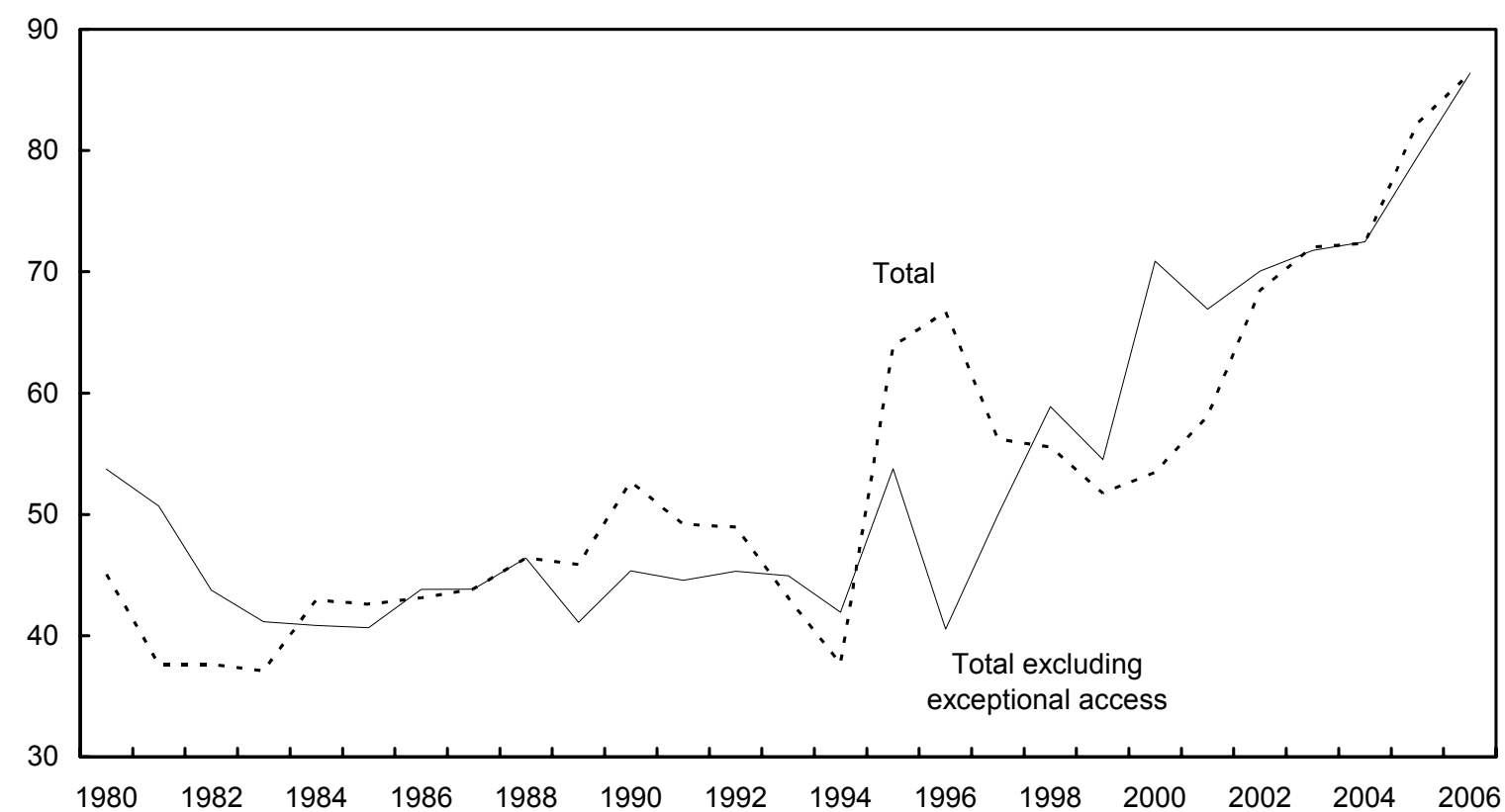

GRA Fund Credit Outstanding: Alternative Trends (in billions of SDRs)

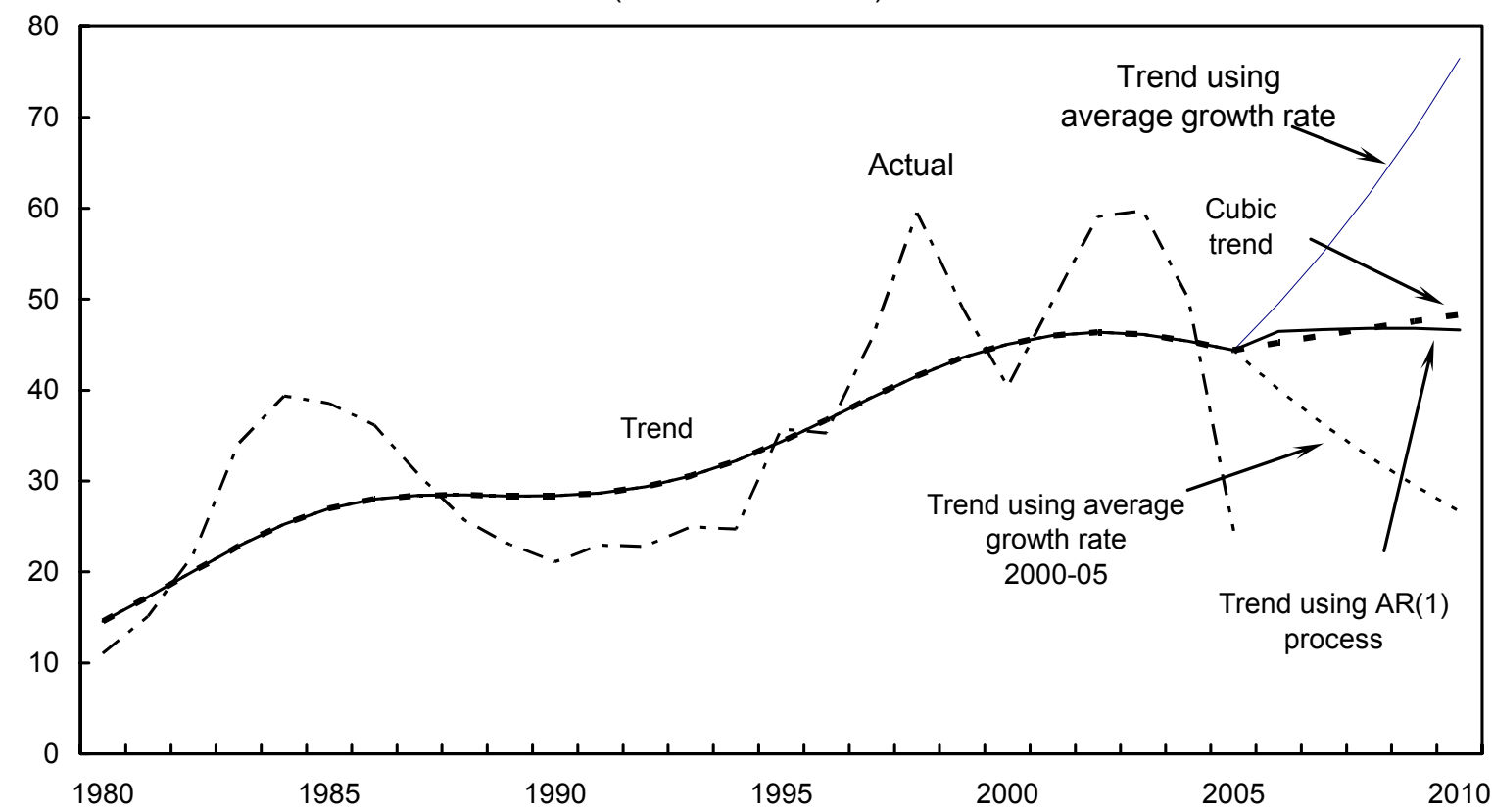

Sources: International Monetary Fund, IFS database; and staff estimates.

1/ 2006 data as of November 2006. 
IMF credit outstanding and various explanatory variables capturing the average economic performance of this group of countries (as well as global market conditions), with convergence to the long-run relationship determined by autonomous dynamics (that depend upon the distance from the long-run relationship) and on short-run factors.

Yet there are caveats to this approach. First, as noted above, the group of countries needs to be sufficiently homogenous that IMF credit outstanding can be related to the aggregate (i.e., average) economic performance of the group. ${ }^{14}$ Although the group consists of middleincome countries, they are quite diverse, with quotas ranging from SDR 20 million to SDR 6.4 billion, GDPs from US\$1 billion to US $\$ 2,000$ billion, and potentially very different external financing needs.

Second, given that - at any moment - a member either does or does not access IMF credit, in what sense can there be short-run and long-run dynamics of total IMF credit outstanding? Here, an analogy to macroeconomic models of unemployment may be useful. At any moment, an individual is either employed or unemployed - and the probability that he enters or exits a spell of unemployment depends on a variety of factors - both macroeconomic and idiosyncratic. Nevertheless, it makes sense to model the short-run and long-run response of the aggregate unemployment rate to macroeconomic factors - on the assumption that the idiosyncratic shocks average out across individuals. Likewise, short-run and long-run dynamics of aggregate IMF credit can be modeled as functions of global conditions and the average economic performance of potential GRA-users, although with the important caveat that national unemployment rates represent the aggregation (with equal weight) of millions of individuals - not of some 50 countries of very different sizes.

Third, the shift towards fewer but larger programs in recent years suggests that the time series process underlying aggregate UFR may have changed over time-yet the analysis treats the process as a single series spanning the period 1980-2005. Indeed, there is evidence that the time series process of aggregate UFR during periods of large exceptional access programs differs from process during other times - though this distinction is less useful when projecting future UFR since which process will pertain is difficult to forecast (Appendix I).

Fourth, beyond exceptional access policy — which affects the amount of IMF financing made available - other IMF policy changes in recent years, including surcharges on IMF resources outstanding, time-based repurchase expectations, and post-program monitoring are likely to have influenced members' repurchases behavior. ${ }^{15}$ These are difficult to capture econometrically as these policy changes are too recent, but could help account for some of

\footnotetext{
${ }^{14}$ For example, suppose that Fund credit outstanding is related to the external debt ratio and that, between two periods, this debt ratio does not change because one country's external debt increases while another's decreases - then the model would imply that Fund credit outstanding should not change either. But the country with the rising debt ratio may be a large, systemically important country that experiences a capital account crisis requiring large Fund access - which would not necessarily be offset by the lower use of Fund credit by the country with the falling external debt ratio (particularly since UFR cannot be negative).

${ }^{15}$ See IMF (2000), IMF (2002a), and IMF (2003).
} 
the early repurchases currently being made by members with IMF credit outstanding. Finally, there are only 25 observations given the estimation period of 1980-2005; while it is possible to extend the time series backwards, the assumption of a stable series becomes less tenable.

With these caveats in mind, a long-run relationship is estimated between the logarithm of IMF credit outstanding and external debt and IMF quota (in percent of GDP), short-term debt (in percent of reserves), and the IMF's rate of charge relative to the 10-year U.S. corporate bond yield (which proxies for the cost of IMF resources relative to market financing). ${ }^{16}$ These variables are computed for the group of potential GRA-users, over the period 1980-2005 (Table 1, top panel). Since each of these variables is individually non-stationary, standard statistical inferences (e.g., t-statistics) are not valid (Phillips (1986)). The stationarity of the residuals from the cointegrating vector, however, indicates that a cointegrating relationship exists. In particular, IMF credit outstanding to this group of countries increases as they have more external debt, lower foreign exchange reserves (in relation to short-term debt), a larger IMF quota, and a lower IMF rate of charge. This is intuitive, since these countries' balanceof-payments need is likely to be increasing in their external debt (in relation to reserves), while their willingness to keep credit outstanding is decreasing in the rate of charge. As regards the quota variable, this may be proxying for trade and financial openness, which may be a determinant of the demand for UFR; indeed, substituting trade openness for Fund quota yields very similar results.

Short-run factors influencing the speed of convergence to the long-run relationship are postulated to depend upon terms of trade shocks, the change in the current account balance, and the change in reserves (in months of imports). Of these, only the change in reserves is statistically significant although all variables have the correct sign. A positive terms of trade shock is associated with less demand for IMF credit while a decrease in reserve cover or an improvement in the current account balance are both associated with greater use of IMF credit. While the latter may appear counterintuitive, it is consistent with the empirical finding that the current account deficit typically narrows in the run up to a IMF-supported programeither because the withdrawal of private financing forces external adjustment or because national authorities tighten policies to promote adjustment before turning to the IMF. ${ }^{18}$

Comparing actual levels of IMF credit outstanding to the model's long-run prediction (Figure 4, top panel), it is evident that much of the very high level of UFR over the

\footnotetext{
${ }^{16}$ The IMF's rate of charge includes the adjusted rate of charge plus the outstanding-credit weighted average of surcharges. As regards the corporate bond yield, while the emerging market bond spreads (EMBI) would be preferable, it is not available for most emerging market—let alone middle-income - countries over the sample period. Using the 10-year U.S. Treasury bill rate instead yields very similar results.

${ }^{18}$ See Ghosh et al. (2005).

${ }^{20}$ If the coefficients for the demand for total Fund credit are imposed in the regression of Fund credit excluding exceptional access, then the likelihood ratio statistic is not significant.
} 
Table 1. Determinants of changes in Fund credit outstanding (1980-2005)

\begin{tabular}{|c|c|c|c|}
\hline & $\begin{array}{c}\text { Fund credit } \\
(1980-2005) \\
{[1]} \\
\end{array}$ & $\begin{array}{c}\text { Fund credit } \\
(1980-2002) \\
{[2]} \\
\end{array}$ & $\begin{array}{c}\text { Fund credit } \\
\text { excluding exceptional access } \\
(1980-2005) \\
{[3]}\end{array}$ \\
\hline \multicolumn{4}{|l|}{ Long-run coefficients $1 /$} \\
\hline $\begin{array}{l}\text { Total debt } \\
\text { (in percent of output) }\end{array}$ & 0.65 & 0.73 & 0.69 \\
\hline $\begin{array}{l}\text { Short-term debt } 2 / \\
\text { (in percent of reserve assets ) }\end{array}$ & 0.09 & 0.07 & 0.23 \\
\hline $\begin{array}{l}\text { Fund quota } \\
\text { (in percent of output) }\end{array}$ & 0.29 & 0.14 & 0.15 \\
\hline $\begin{array}{l}10 \text { YR Corporate bond premium minus } \\
\text { Fund's rate of charge (in percent, t-1) }\end{array}$ & 0.01 & 0.03 & 0.02 \\
\hline \multicolumn{4}{|l|}{ Short-run dynamics } \\
\hline $\begin{array}{l}\text { Change in Fund credit } \\
\text { outstanding }(\mathrm{t}-1)\end{array}$ & $0.53 * * *$ & $0.36 *$ & $0.35 * * *$ \\
\hline $\begin{array}{l}\text { Change in the terms of } \\
\text { trade }\end{array}$ & -1.05 & -0.73 & -0.54 \\
\hline $\begin{array}{l}\text { Change in the current account } 2 / \\
\text { (in percent of output, } t-1 \text { ) }\end{array}$ & 3.83 & 2.09 & 5.21 \\
\hline $\begin{array}{l}\text { Change in reserves } 2 / \\
\text { (in percent of imports, } t-1 \text { ) }\end{array}$ & $-2.73 *$ & -1.43 & $-3.76 * * *$ \\
\hline \multicolumn{4}{|l|}{ Diagnostics } \\
\hline Nobs. & 25 & 22 & 25 \\
\hline R squared & 0.71 & 0.68 & 0.80 \\
\hline $\begin{array}{l}\text { Phillips-Perron Unit Root Statistic } \\
\text { for the Residuals 3/ }\end{array}$ & $-4.01 * *$ & $-3.67 * *$ & $-3.32 * *$ \\
\hline
\end{tabular}

Note: $* * *$ significant at 1 percent; $* *$ significant at 5 percent; and $*$ significant at 10 percent.

1/ Statistical Inference cannot be made on the unit root variables separately Phillips-Perron unit root test statistics for these variables indicate non-stationarity and are as follows: external debt (-2.3); short-term debt (-2.1);

Fund quota (-1.8); and the corporate bond premium (-2.3).

2/ Excluding China.

3/ This test indicates that a cointegrating vector exists between the long-run determinants.

period 2001-2005 should have been expected to be temporary in that it far exceeded the level implied by the equilibrium cointegrating relationship. Whereas the long-run relationship would suggest aggregate UFR of around SDR 40 billion in 2001-03, actual credit outstanding was in the range of SDR 50-63 billion. Thus, the model's autonomous dynamics would - ceteris paribus - tend to decrease UFR towards the level implied by the 
Figure 4. Fund Credit Outstanding: Actual and Fit of Time-series Model (In millions of SDRs)
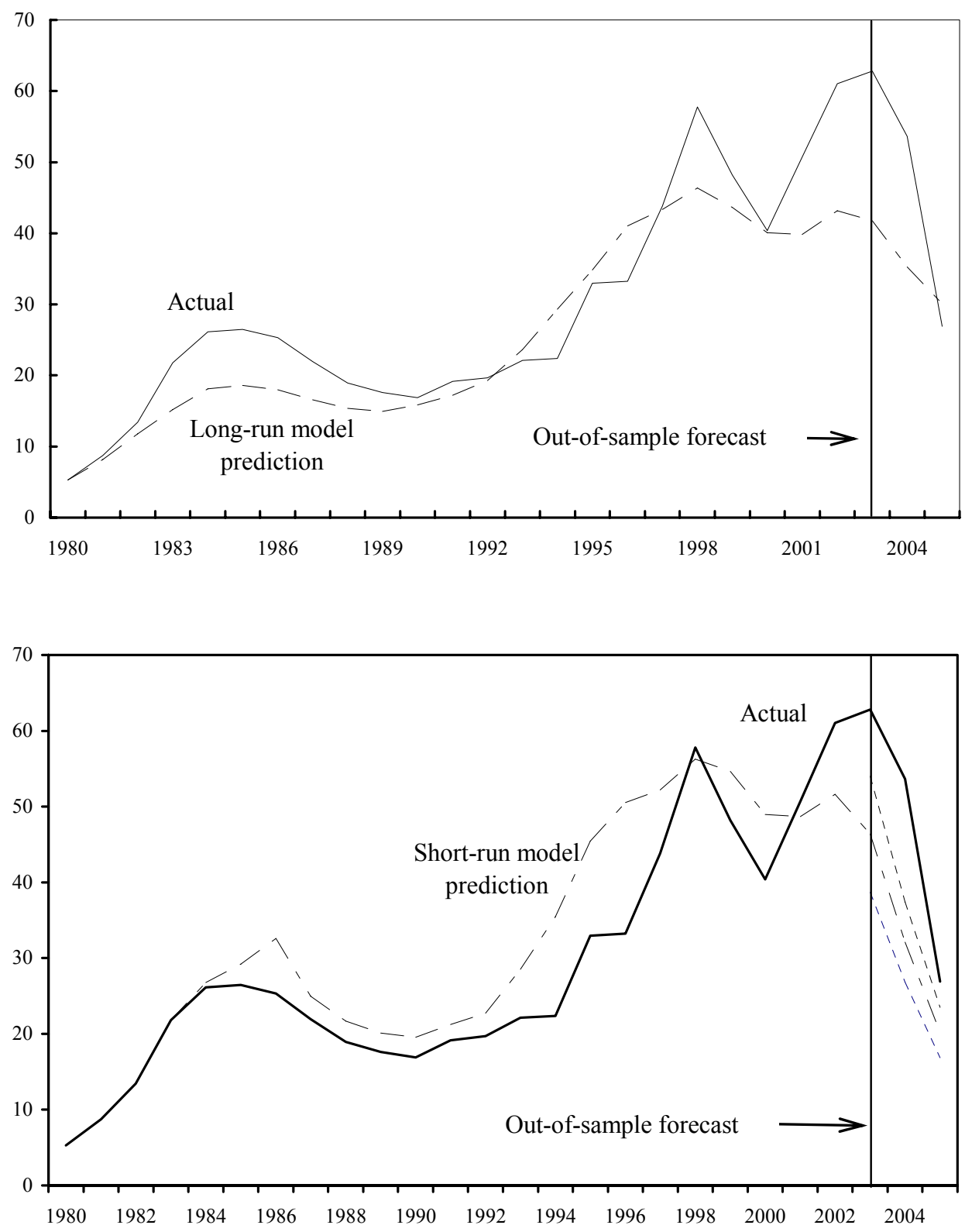

Sources: International Monetary Fund, IFS database, and staff estimates 
long-run relationship. Indeed, taking account of short-run dynamics, actual UFR exceeded the model's prediction by an average of SDR 11 billion over the period 2001-05.

Overall, the fit of the model is good, accounting for some 68 percent of the variation in IMF credit outstanding (and over 80 percent if exceptional access programs are excluded). Given the large number of variables relative to observations, however, a more telling test of the model's performance is the accuracy of out-of-sample projections. For this purpose, the model was re-estimated over the period 1980-2002, and the coefficients used to project IMF credit outstanding for the period 2003-05. ${ }^{20}$ Although — as noted - the model does not fully account for the very high levels of IMF credit outstanding during 2001-05, it does capture the main dynamics correctly. While the predicted peak of SDR 52 billion in 2002 is considerably below the actual peak of SDR 63 billion in 2003, the model does anticipate the subsequent downturn in UFR. The main contributors to the decline in the demand for Fund resources over the 2003-05 period are the fall in the ratio of total debt to output and the sharp rise in reserve assets also resulting in a decline in the ratio of short-term debt to reserves. Indeed, long run determinants of IMF credit were projected to contribute to a decline of 60 percent over the 2003-05 period while short run determinants were projected to to contribute an additional 85 percent. In the event, IMF credit fell by over 300 percent.

\section{Modeling Individual Members' Use OF IMF ResourCeS}

To complement the time series analysis of aggregate UFR, an alternative approach estimates the expected use of IMF resources by individual countries, and then aggregates across the eligible membership. Specifically, in the first stage, a logit model is used to estimate the likelihood that a member will experience balance of payments difficulties requiring an IMFsupported program. ${ }^{21}$ In the second stage, a regression model is used to calculate the expected approved access to IMF resources, with the inverse Mills ratio from the logit estimation controlling for the sample selection bias. ${ }^{22}$ Finally, approved access is mapped into IMF credit outstanding by assuming average disbursement and repayment profiles.

\footnotetext{
${ }^{21}$ An alternative approach would be to estimate Fund access using a Tobit model. However, while this would provide the expected access level, it would not provide the likelihood of a program and the expected level of access (conditional on a program) separately. Moreover, a Tobit model would treat cases where the country does not have a program as a program with zero access.

${ }^{22}$ The Heckman two-stage approach adopted here assumes that there is some process that determines whether access is observed (see Heckman, 1979). An intuitive explanation of the Heckman approach, including the use of the inverse Mill's ratio (IMR), can be found in the Nobel citation by the Royal Swedish Academy of Sciences (2000, pp. 4-5). The Heckman approach can be interpreted as a special case of the omitted variable problem - with the selection criteria being the omitted factor. The first stage estimates selection, with the IMR entering in the second stage as the (previously) omitted variable. In this case, the statistically significant coefficient on the IMR variable indicates a non-random selection of countries into having IMF-supported programs. The sign of the coefficient in the IMR - see Dolton and Makepeace (1987) - describes the correlation between unobservables in the selection and outcome regressions; in this case, the negative coefficient implies that the unobservable characteristics that lead to higher access also lower the probability of having an IMFsupported program. Dubin and McFadden (1984) is an early and intuitive application of this procedure to residential electric appliance holdings and consumption.
} 
In contrast to the time series analysis, which is based on IMF credit outstanding, the dependent variable here is IMF access (a binary variable in the first stage, and the logarithm of the access amount at the time of program approval in percent of GDP). Original access approved does not map directly into disbursements because the program may go off track or because national authorities choose to treat the arrangement as precautionary (or they otherwise choose to stop drawing); conversely, disbursements may exceed the original approved amount if the arrangement is augmented. Historically, the ratio of disbursed amounts to approved access has ranged from about 70 percent (1980-90) to about 80 percent (1990-2005); in the projections below, the ratio is therefore set at 75 percent.

Table 2 reports coefficient estimates for the program-selection logit specification. A country is more likely to have a IMF-supported program the higher its external debt, the lower its reserve coverage of imports, the greater the fiscal and external adjustment it undertakes, the higher (lower) are oil prices for oil importers (exporters), and the higher is a country's inflation rate. Lower output growth or deteriorating terms of trade are also associated - albeit not statistically significantly — with a greater likelihood of a program. ${ }^{23}$

The model's goodness-of-fit, calculated as the McKelvey-Zavoina pseudo- $\mathrm{R}^{2}$ statistic, is $0.21 .^{24}$ More generally, a commonly used statistic of goodness-of-fit is the number of observations where the member had a program and the predicted probability was above a threshold (that is usually set equal to the frequency of programs in the sample - which is 20 percent for this sample). The statistic is potentially misleading as a test of the model's predictive power for any individual member because the model predicts probabilities, not outcomes. ${ }^{25}$ Thus, when a member has a predicted probability of more than 20 percent, this does not necessarily imply that the member will have a program (or that, if it does, the model was necessarily correct in predicting the program). However, across the sample, if the predicted probability of a program is 20 percent, then, on average, around 20 percent of the sample should have programs. Thus, the predicted probability can be used to forecast the aggregate portfolio - but not whether an individual member is going to have a program.

With this important caveat regarding the interpretation of the results, Table 3 reports instances where the predicted probability is above the threshold and the member indeed had a program (67 percent of cases) and, conversely, where the predicted probability is below the threshold and the member did not have a program (73 percent of cases); out of sample, the corresponding statistics are 70 percent and 65 percent respectively. In a number of instances,

\footnotetext{
${ }^{23}$ Indicators of political and economic proximity, such as UN votes and trade shares with the U.S. or Western Europe, have no statistically significant effect on the likelihood that a country will request an IMF-supported program or on the size of IMF lending. Thus, the role of political and economic proximity discussed by Barro and Lee (2005) does not appear to hold in better specified models of program selection and access.

${ }^{24}$ The literature contains many alternative measures of goodness-of-fit for use with equations with discrete dependent variables. There is, however, no consensus as to the relative merits of alternative measures and most of the measures proposed have a theoretical upper bound well below unity. See Estrella (1998) and Windmeijer (1995) for a discussion of various of goodness-of-fit measures in discrete choice models.

${ }^{25}$ For a discussion see Train (2003).
} 
such as Paraguay (in 2003) and Uruguay (in 2005), the implied probability is just below the threshold (which is set to the sample frequency of programs); in other cases, the predicted probability is above the threshold in the year preceding the program approval. ${ }^{26}$

Table 2. Selection Stage: Decision to Request an SBA/EFF

(based on GRA arrangements over the period 1972-2005)

\begin{tabular}{lrc}
\hline Dependent variable: GRA $=1$, No GRA $=0$ & Coefficient $\mathrm{z}$ value \\
\hline Program previous period & 0.7136 & $2.88^{* * *}$ \\
Program previous period with duration greater than 1.5 years & -1.7372 & $-3.29 * * *$ \\
Program two years ago & 1.1905 & $6.10^{* * *}$ \\
Program two years ago with duration greater than 2.5 years & -1.0088 & $-2.16^{* *}$ \\
Oil prices, real; lagged oil price deviation times dummy for oil exporters & -0.6509 & $-1.69 *$ \\
Oil prices, real; lagged, deviation from trend & 0.4399 & $1.93 * *$ \\
Real interest rates; lagged & 0.0021 & 0.07 \\
Terms of trade; growth rate, lagged & -0.0008 & -0.16 \\
Total external debt (in percent of GDP); lagged & 0.0099 & $3.36 * * *$ \\
Reserve cover in months of imports; lagged & -0.1073 & $-2.19 * *$ \\
Private capital flows, net of FDI; lagged & 0.0185 & 1.51 \\
Private capital flows, net of FDI; change & 0.0004 & 0.02 \\
Current account balance (in percent of GDP); change & 0.0606 & $2.61 * * *$ \\
General government balance (in percent of GDP); change & 0.0758 & $3.10 * * *$ \\
Change in real GDP growth rates & -0.0055 & -0.31 \\
Broad money to GDP ratio; change & 0.0051 & 0.25 \\
Inflation rate ( $\pi /(1+\pi)$ ) & 0.0165 & $1.64 *$ \\
Constant & -1.8824 & $-7.17 * * *$ \\
Number of observations & 1185 & \\
LR chi2 (17) & $142.05 * * *$ \\
McKelvey and Zavoina's pseudo R ${ }^{2}$ & 0.21 & \\
\hline
\end{tabular}

Note: $* * *$ significant at 1 percent; $* *$ significant at 5 percent; and $*$ significant at 10 percent.

Predicting whether and when a member will have a IMF-supported program is only the first step. The next step is the level of access to GRA resources that will be granted. Within the normal access limits (annual access of 100 percent of quota, and a cumulative limit of 300 percent of quota), access is granted according to the member's balance of payments need, its capacity to repay the IMF, and its outstanding IMF credit, repayment record and previous use of IMF resources. Exceptional access beyond the access limits may be granted if the member has a balance of payments need and fulfills certain criteria. ${ }^{28}$ For most programs in the $1980 \mathrm{~s}$, access as a percentage of quota averaged 30 percent, rising to 50 percent in the 1990s. The 1990s also saw large capital account crisis programs, with

\footnotetext{
${ }^{26}$ For instance, a program is "predicted" in Romania in 2003 (instead of the actual 2004 program), Paraguay in 2005 (instead of 2006), Gabon in 2003 (instead of 2004), Uruguay in 2004 (instead of 2005), and Ukraine in 2005 (instead of 2004).

${ }^{28}$ See pages 335-349 of IMF (2005b) for discussions of access policy.
} 
access many multiples of quota, which are especially difficult to handle because there are only 16 such cases in a sample of 236 arrangements, and it is hard to find variables that can both explain the amount of access provided and that are themselves readily forecastable.

Table 3. Access Model, Type I and Type II Errors

In-Sample Prediction (1972-2005)

A. Classification of individual observations

\begin{tabular}{|c|c|c|c|c|}
\hline & \multicolumn{2}{|c|}{ Country had } & \multirow[b]{3}{*}{412} \\
\hline & & $\overline{\text { SBA }}$ & No SBA & \\
\hline \multirow{2}{*}{ 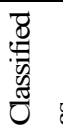 } & SBA & 157 & 255 & \\
\hline & No SBA & 79 & 694 & 773 \\
\hline & & 236 & 949 & 1185 \\
\hline
\end{tabular}

B. Type I and type II errors (in percent)

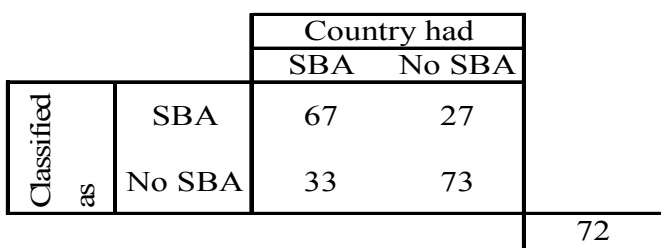

Out-of-Sample Prediction (estimation 1972-2002; prediction 2003-2005)

A. Classification of individual observations

\begin{tabular}{|c|c|c|c|c|}
\hline & \multicolumn{2}{|c|}{ Country had } & \\
\hline & & $\overline{\mathrm{SBA}}$ & No SBA & \\
\hline \multirow{2}{*}{ 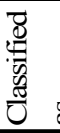 } & SBA & 14 & 49 & 63 \\
\hline & No SBA & 6 & 90 & 96 \\
\hline & & 20 & 139 & 159 \\
\hline
\end{tabular}

B. Type I and type II errors (in percent)

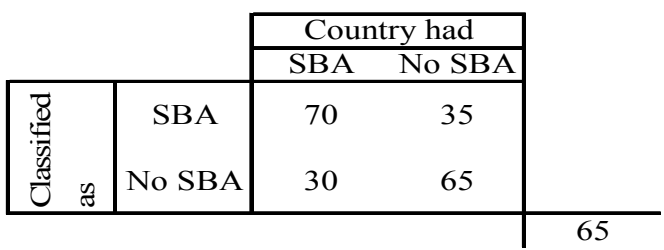

The access regression uses a generalized least squares estimation. As shown in Table 4, access (as a percentage of the country's GDP) is positively and statistically significantly related to the country's initial external debt and the external adjustment it undertakes in the year of program approval (relative to its current account deficit in the previous three years). IMF quota and the ratio of short-term debt-to-reserves also enter the regression with positive, albeit statistically insignificant, coefficients. Finally, to help capture exceptional access in the large capital account crisis programs, a dummy variable is defined for countries that are "systemically large" (proxied by the country being in the top decile of the sample in terms of U.S. dollar value of GDP) and whose external debt exceeds 40 percent of GDP. ${ }^{29}$ Although this dummy variable is highly significant (with its coefficient implying that access is, on average, 4 percent of GDP higher for such programs, ceteris paribus), it cannot fully capture the exceptionally large access provided in some capital account crises. The regression tracks movements in GRA access, explaining about 20 percent of the variation in the dependent variable.$^{30}$ Yet, in-sample, the model estimates that the programs approved during the period 2000-05 would have involved access for a total of SDR 53 billion, which compares with the

\footnotetext{
${ }^{29}$ Empirical studies suggest that, for market borrowers, there is an appreciable increase in the probability of a debt crisis when external debt exceeds 40 percent of GDP—see IMF (2002a).

${ }^{30}$ Replacing IMF quota with an openness variable (defined as a sum of exports and imports in percent of GDP) for reasons discussed earlier in Section III, however, does not change the results. The coefficient on the openness variable remains statistically insignificant, with other variables retaining their results; the measured $\mathrm{R}^{2}$ also does not change.
} 
total for programs approved during that period of SDR 65 billion. Applying the predicted probability weights, this translates into a predicted average UFR outstanding of SDR 27 billion-compared to an actual of about SDR 50 billion. $^{31}$

Table 4. Access Stage: Determinants of Access Levels in an SBA/EFF (based on access levels under GRA arrangements over the period 1972-2005)

\begin{tabular}{lrc}
\hline Dependent variable: Access amount as percent of GDP 1/ & Coefficient z value \\
\hline Quota & 0.0000 & 1.35 \\
Total debt to GDP; lagged & 0.0015 & $3.74 * * *$ \\
Change in current account balance (in percent of GDP); relative to past 3 years & 0.0054 & $1.77^{*}$ \\
Short-term debt to reserves; lagged & 0.0058 & 1.33 \\
Inverse Mills ratio & -0.0995 & $-6.94 * * *$ \\
Dummy for large country, high debt country & 1.3984 & $19.13^{* * *}$ \\
Time trend & -0.0033 & $-3.39 * * *$ \\
Constant & 0.3120 & $7.35 * * *$ \\
Number of observations & 1185 & \\
Number of countries & 53 \\
Wald chi2(8) & $583.83 * * *$ \\
Pseudo R2 & 0.19 & \\
\hline
\end{tabular}

Note: $* * *$ significant at 1 percent; $* *$ significant at 5 percent; and $*$ significant at 10 percent. 1 / The dependent variable is the natural logarithm of one plus access to GDP in percentage terms.

To generate out-of-sample projections, the program selection logit is used to generate the probability that the member will have a program and, based on those probabilities, the associated level of access; it is also assumed that a country cannot have new programs in two consecutive years. For the period 2003-05, the model's mean prediction of aggregate access is SDR 7.9 billion compared to actual access of SDR 14.3 billion-the major sources of error are that the model fails to predict two large programs (Colombia and Uruguay, which together total SDR 2.3 billion) and underestimates access in Argentina by about SDR 4 billion (Figure 5). ${ }^{32}$ This mean prediction of SDR 7.9 billion assumes that the member has a program when the predicted probability exceeds the threshold — which, as discussed above, may be legitimate when considering the aggregate portfolio though not for individual predictions. Using the point estimates of the probabilities instead yields an even lower estimate of about SDR 4 billion for the period 2003-05 because some of the high access programs that were realized receive a low probability weight (albeit higher than the threshold probability).

\footnotetext{
${ }^{31}$ Predicting that the member has a program when the predicted probability exceeds the threshold (and no program whenever the probability is below the threshold) yields a predicted average UFR outstanding of SDR 34 billion instead of SDR 27 billion.

${ }^{32}$ See caveat regarding the interpretation of predictions for individual programs earlier in this section.
} 
Figure 5. Approved GRA Access (In billions of SDRs; 1972-2005)

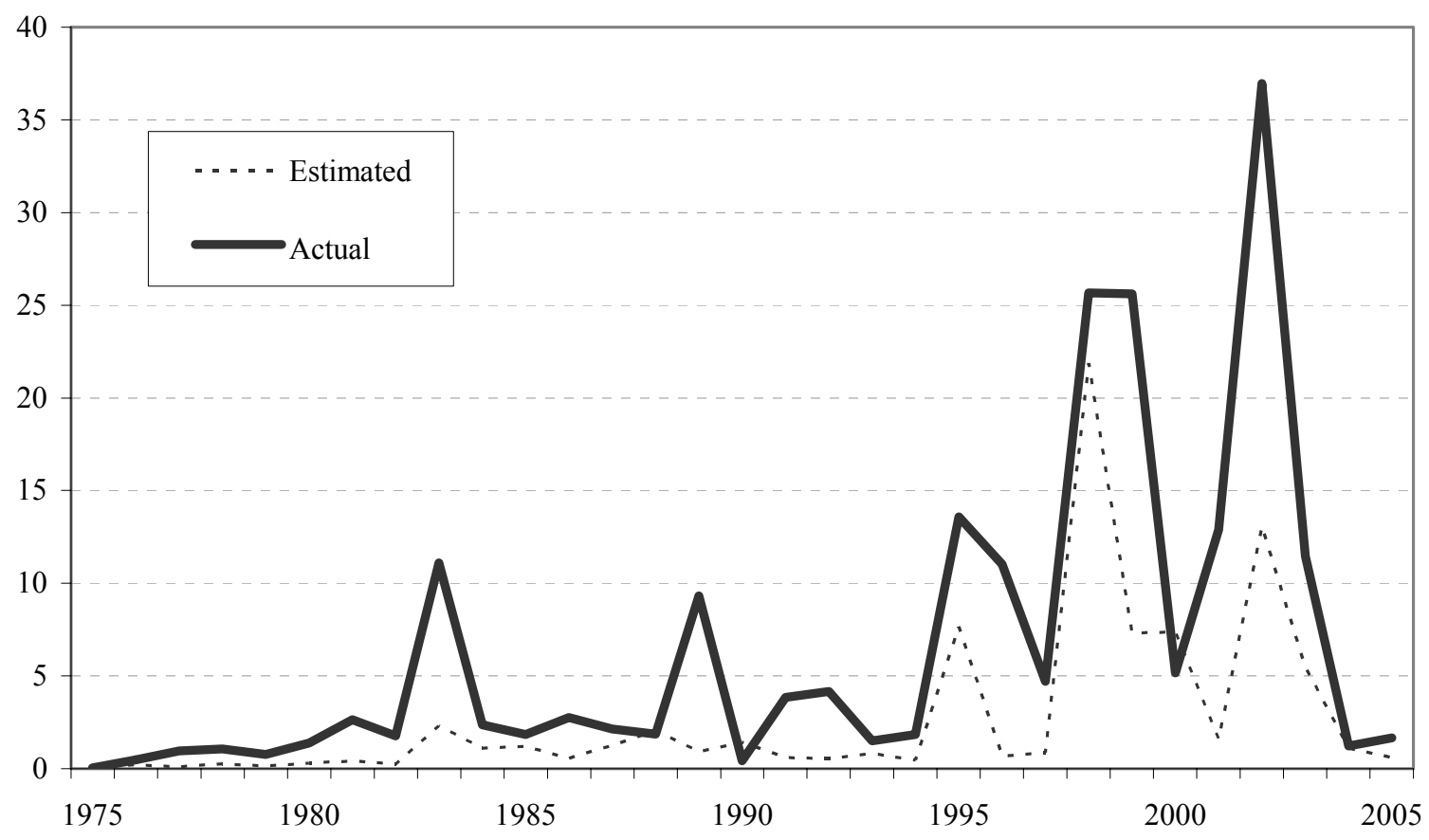

Source: WEO and IMF staff estimates.

\section{Medium-Term Projections}

The models developed in the preceeding sections can be used to generate medium-term projections of use of IMF resources. Such projections require forecasts of the explanatory variables; for most variables, country teams' WEO forecasts are used-the exceptions being the corporate bond yield and IMF quota, which are kept constant at their mid-2006 values. It bears emphasizing, however, that the projections of aggregate UFR will be only as good as the underlying forecasts of the explanatory variables. Indeed, there are several sources of uncertainty inherent in the projections of aggregate UFR. First, within each model, even conditional on the forecasts of the explanatory variables, the regressions have residuals with zero mean and variance given by the standard error of the regression. Second, as noted, there is uncertainty surrounding the forecasts of the explanatory variables. Third, the model used for the projections may be fundamentally misspecified. Finally, although the models are estimated on the use of IMF resources, it is possible that members' response to balance of payments difficulties has shifted over time. In particular, recent developments in selfinsurance and regional reserve pooling may provide an alternative to use of IMF resources.

To address the first of these sources of uncertainty, the baseline projections reported below include 90 percent confidence bands, derived by stochastic simulations using bootstrapping techniques (the entire probability distribution of GRA credit outstanding is shown as well). Thus, conditional on the explanatory variables, the probability of aggregate UFR being higher (respectively lower) than the upper (respectively lower) band is less than 5 percent. 
Addressing the second source of uncertainty - forecast errors in the explanatory variables - is more tricky. A number of previous studies have found that - with the exception of forecasts for advanced economies - WEO projections typically exhibit some optimistic bias, especially as regards variables such as output growth or external debt ratios. ${ }^{33}$ This would imply a downward bias in projections of the likelihood of a country needing IMF support and hence of aggregate use of IMF resources. Therefore, in one of the alternative scenarios considered below, a correction (based on historically observed WEO projection biases) is applied to the forecasts of the explanatory variables. A further difficulty is that country teams' WEO projections may represent the average of a bimodal forecast - good and bad scenarios; unfortunately, WEO only provides country teams' central projection, not the distribution of that projection. To the extent that there are threshold effects in the determinants of balance of payments problems (although the estimated model does not exhibit such threshold effects), the use of the central forecasts could lead to an incorrect forecast of UFR. ${ }^{34}$

Finally, the risk that the model is fundamentally misspecified is the most difficult to deal with, but it is somewhat mitigated here by the use of two distinct approaches - the time series aggregate UFR model and the individual members' program and access model. Nevertheless, these various sources of possible error imply that any projections of aggregate use of IMF resources will be subject to a high degree of uncertainty.

\section{A. Baseline Projection}

The time series model suggests that the end-2006 stock of IMF credit outstanding of SDR 10.6 billion is well below the level implied by the long-run relationship of SDR 24 billion (Figure 6, top panel). However, given expected declines in middle-income countries' external debt ratios and rising reserves coverage of short-term debt, the implied long-run value of IMF credit itself declines to SDR 16.5 billion by 2010. Meanwhile, short-run dynamics lead the stock of IMF credit to increase from the 2006 level and converge towards the 2010 longrun value. Thus, the time series model predicts that the outstanding stock of IMF credit should reach SDR 10 billion by 2010, with the 90 percent confidence interval (based on the

\footnotetext{
${ }^{33}$ IMF (2005a), which examined biases in Fund staff projection of debt, found that external debt-to-GDP ratios were underprojected by almost 1 percent over the 1 -year horizon, rising to 3 percent in the 3 -year ahead projections. To this bias, lower-than-projected GDP growth contributed $1 / 2$ a percent at a 1 -year horizon rising to $2 \frac{1}{2}$ percent over five years.

${ }^{34}$ For instance, suppose there is a threshold effect whereby a balance of payments problem (and thus need for UFR) is more likely once the current account deficit exceeds 5 percent of GDP. Suppose, further, that the country team has a bimodal forecast for the current account balance of +5 percent of GDP (with 0.5 probability) and -5 percent probability (with 0.5 probability) - yielding an average projection for the current account deficit of 0 percent of GDP. Since this is less than the threshold of -5 percent of GDP, the likelihood of a program is underestimated. However, threshold effects are not apparent in the model estimated above; moreover, it is not clear in which direction the results would be biased if threshold effects were present. If, for example, there is an appreciably lower likelihood of a crisis when reserves exceed a threshold of 100 percent of short-term debt, and the team's average projection was for reserves to be below 100 percent of short-term debt (but the upper mode was above 100 percent of short-term debt), then the model would overestimate the likelihood of a crisis.
} 
Figure 6. Medium-term Projections of Fund Credit Outstanding (In billions of SDRs) 1/

Time-series model

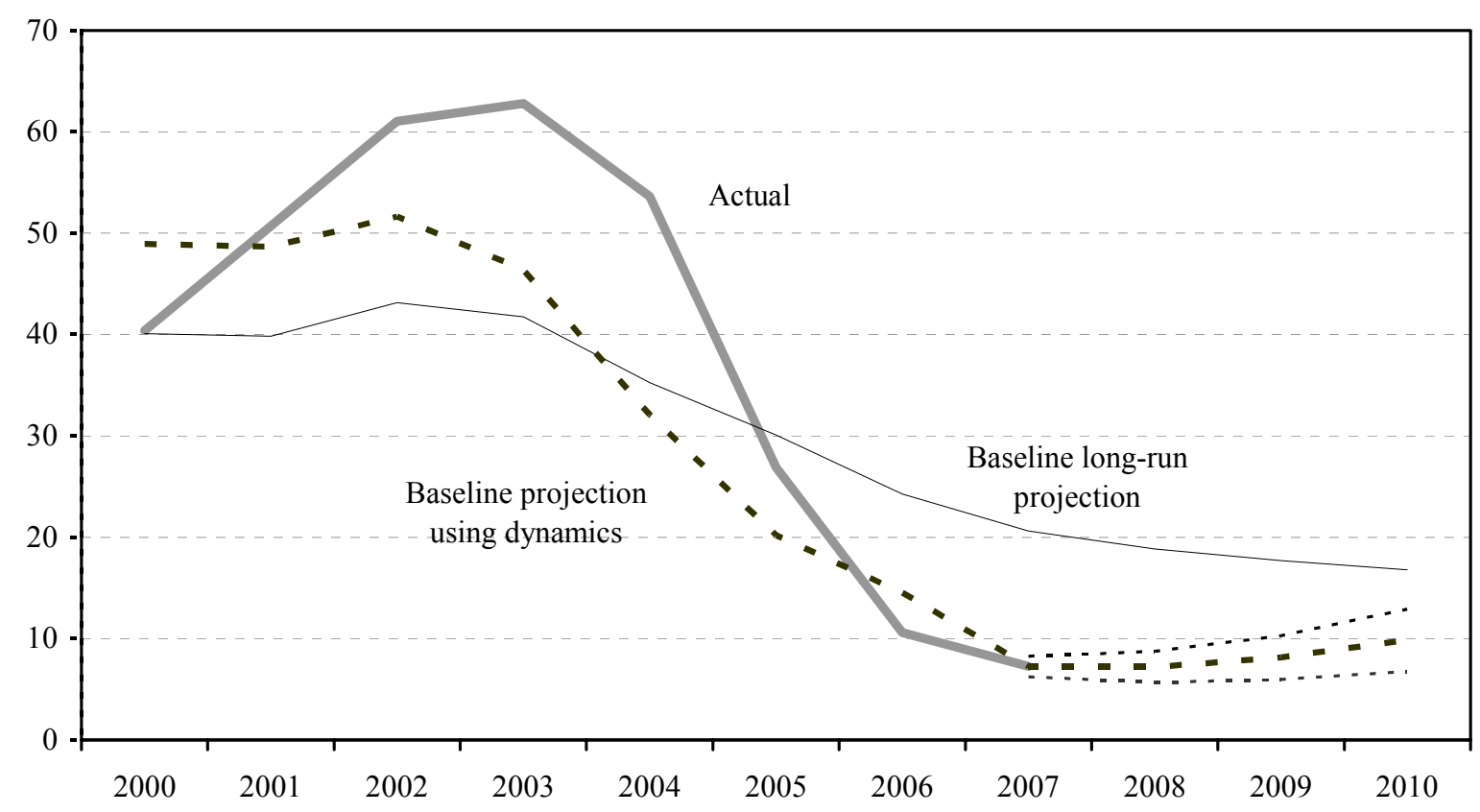

Access model 2/

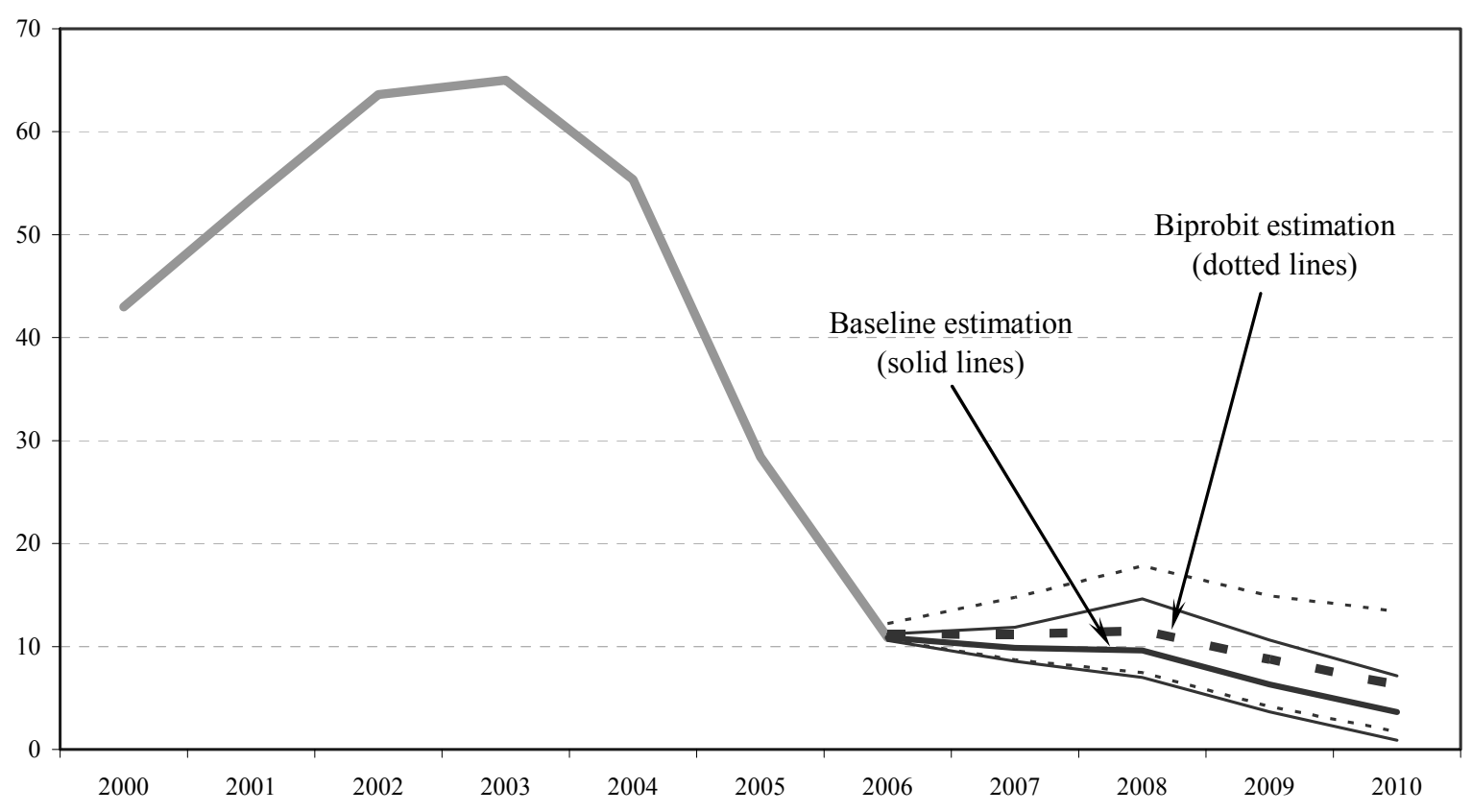

Source: WEO and IMF staff estimates.

1/ Charts include a 5 percent confidence intervals for the projection period 2006-2010.

2/ Includes a baseline (logit) and a biprobit estimation (using Poirier's partial observability model), both with 5 percent confidence intervals. 
regression's residuals) ranging from SDR 6.8 billion to SDR 13 billion. Over the period 2006-2010, IMF credit outstanding would average SDR 8.6 billion.

Turning to the "program selection and access" model, and again applying WEO projections but now for each individual country separately, the model predicts an average of 32 new arrangements over the period 2006-2010, of which 3 would be "exceptional access" programs with systemically large, heavily indebted members. ${ }^{35}$ To generate these projections, the program selection logit is used to generate the probability that the member will have a program. Based on those probabilities, 1,000 stochastic simulations using a binomial random generator are carried out to determine whether a country has a program and the associated level of access. In turn, the level of access if a program exists has a country-specific shock based on bootstrapped errors from the access regression. Although the profile of IMF credit outstanding is a bit different from the time series model, the average level of UFR over the period 2006-2010 is only marginally lower (around SDR 8.1 billion; Figure 6, bottom panel). ${ }^{36}$ Figure 7 depicts the entire probability density function for each year's outstanding UFR as projected by the two approaches in this paper. ${ }^{37}$ The five percent tails of these density functions correspond to the 90 percent confidence intervals depicted in Figure $6 .^{38}$

As a robustness check, a partially observed bivariate model was estimated as an alternative to the first stage; in principle, this enables to take into account better the simultaneous decision by two agents - the country and the IMF - to have an IMF-supported program, though no identifying restrictions are imposed. As Maddala (1983, p. 282) notes, it is still possible to estimate such a partially observed bivariate model, but doing so typically does not produce good parameter estimates. Nonetheless, the estimation is still undertaken and increases the average level of UFR over the period 2006-2010 to SDR 9.8 billion. ${ }^{39}$

\footnotetext{
${ }^{35}$ Predicted in the sense that the implied probability is greater than the sample frequency of 20 percent. However, arrangements are assumed to last two years; thus, the model cannot predict arrangements for the same member in two consecutive years.

${ }^{36}$ Estimating the use of IMF resources by individual members over the same period used in the time series model (1982-2005) provides similar results. Specifically, while the number of observations declines by 20 percent, the coefficient estimates remain broadly unchanged (both in terms of significance and interpretation), and the aggregate use of Fund credit is only marginally different (SDR 7.5 billion instead of SDR 8.1 billion).

${ }^{37}$ Forecasts for the aggregate time series model are obtained by Monte Carlo techniques, with residuals drawn randomly from a normal distribution with mean zero and standard deviation as implied by the regression estimates (1000 rounds are used). Forecasts for the program selection and access model involve two steps; a binomial random generator with a mean equal to the probability of having a Fund-supported program is used in the stochastic probability simulations (1000 rounds are used), and the estimated level of access is bootstrapped using country specific errors from the access estimation (1000 rounds are used).

${ }^{38}$ The 90 percent confidence bands are asymmetric because any individual member's access and use of Fund resources cannot be negative. Hence, if outstanding credit is low, it is less likely to fall further than it is to increase. This is more important for the model of individual members' program selection and access, as the non-negativity constraint is more likely to be binding for an individual member than for the aggregate portfolio.

39 The paper uses the bivariate probit model with partial observability, as considered by Poirier (1980). While the projected UFR for 2010 is higher in the bivariate probit case, SDR 6.3 billion compared to SDR 3.6 billion
} 


\section{B. Scenario Analysis}

It is useful to complement these baseline projections with scenario analysis in order to gauge the sensitivity of the results to specific assumptions. The first scenario applies a correction to the WEO forecasts of the explanatory variables based on historically observed biases - the most important being that the external debt ratio is typically underpredicted. While it does not necessarily follow that current WEO projections will exhibit the same optimistic bias as in the past, the impact on possible use of IMF credit is discernible. For instance, the time series model's baseline prediction for aggregate UFR of SDR 8.6 billion averaged over the period 2006-10 becomes SDR 9.7 billion in this alternative scenario (Scenario I-A; Figure 8, top panel). A second scenario seeks to reproduce the conditions in the run-up to the 1997-98 Asian Crisis. To this end, the same increase in the external debt and short-term debt-toreserves ratio as experienced in the Asian Crisis countries between 1994-1996 is assumed to apply to all countries in the sample (and to persist over the forecast horizon). In this scenario, the predicted UFR rises to SDR 22 billion by 2010, with an average of SDR 12.3 billion for the period 2006-10 (Scenario II-A; Figure 8, top panel).

For the "program selection and access" model, applying the correction to WEO projections raises the average UFR prediction over the period 2006-10 from SDR 8.1 billion in the baseline to SDR 9.1 billion (Scenario I-B; Figure 8, bottom panel). In this scenario, the model predicts an average of 37 arrangements (of which four are exceptional access) over the 2006-2010 period, compared to an average of 32 new arrangements (of which 3 are exceptional access) in the baseline. The sensitivity of the results for use of IMF resources underscores the importance of realistic macroeconomic projections and debt sustainability analyses. Finally, another scenario considers the effects of a significant deterioration in global conditions - specifically, a two standard-deviation shock to oil prices beginning in 2007 and maintained through 2010. Under this scenario, aggregate UFR would be expected to average SDR 9.3 billion over the period 2006-2010, with aggregate UFR in 2010 estimated to be SDR 7 billion - which is about twice the baseline level for 2010 - with much wider confidence bands (Scenario II-B; Figure 8).

in the baseline, the confidence interval is also much wider, ranging from about SDR 1.7 billion to SDR 13.4 billion. Use of the bivariate probit method did not alter the significance of coefficients. However, due to difficulties in convergence, richer identifying restrictions could not be applied. 
Figure 7. Stochastic Simulation of Outstanding Fund Credit (2006-10; GRA only)

Time Series Model

40

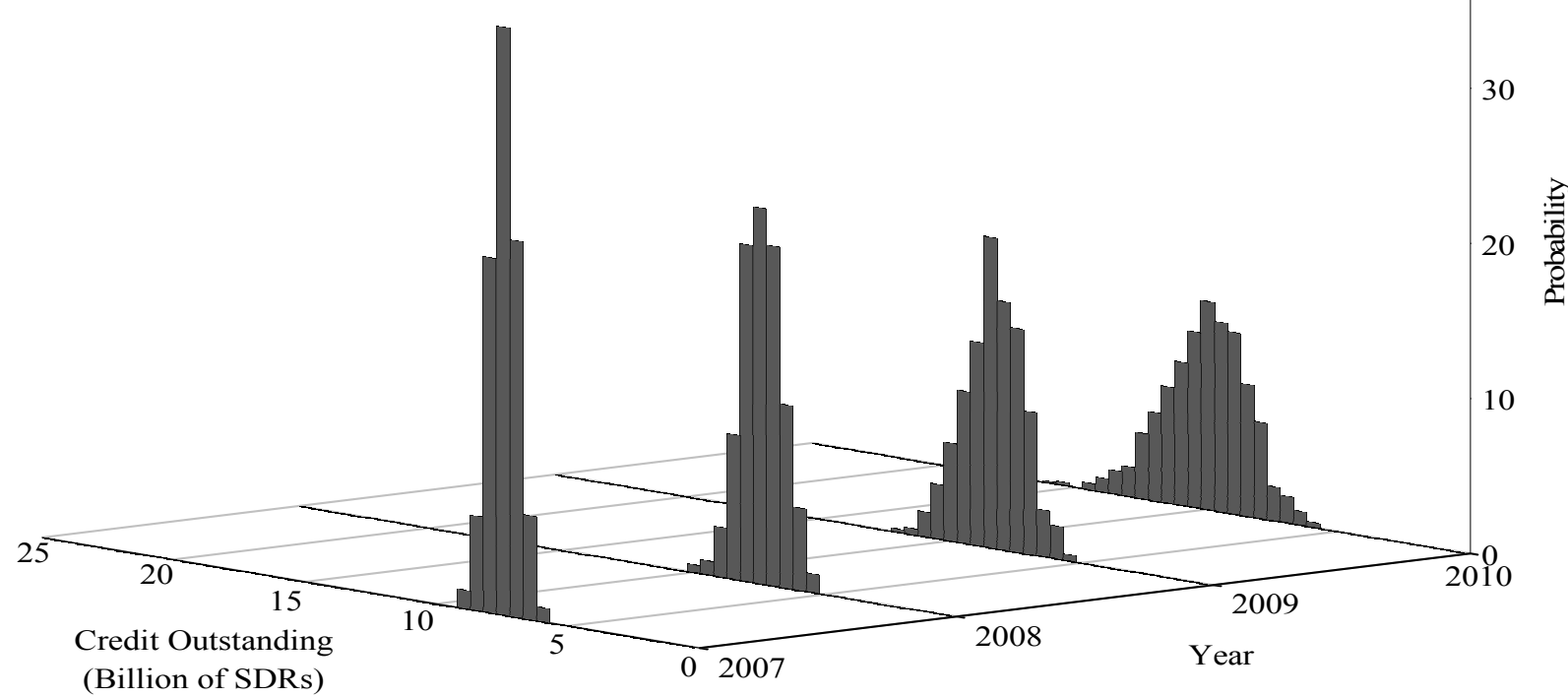

Access Model

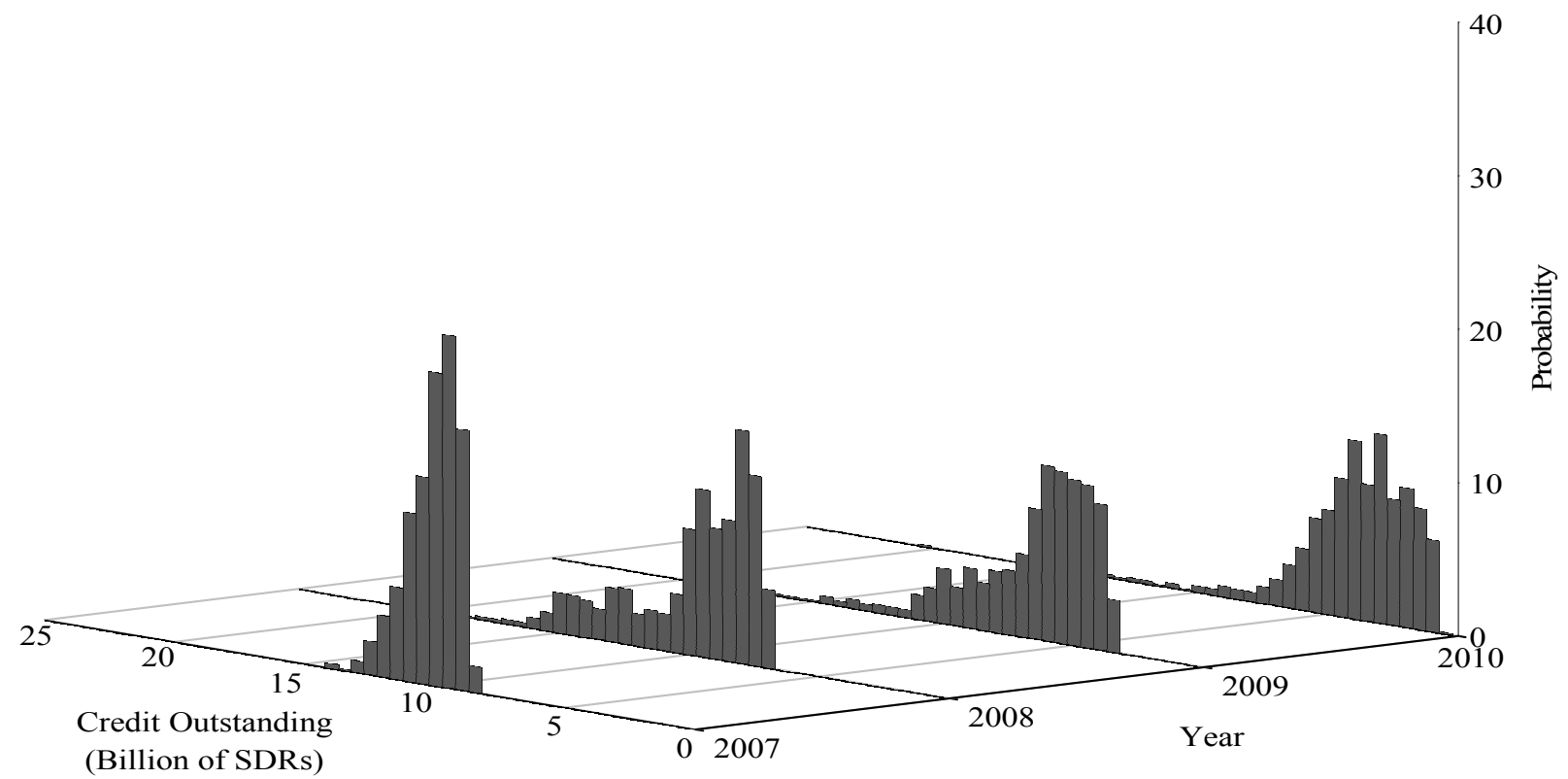


Figure 8. Alternative Scenarios of Fund Credit Outstanding (In billions of SDRs) 1/ 2/

Time-series model

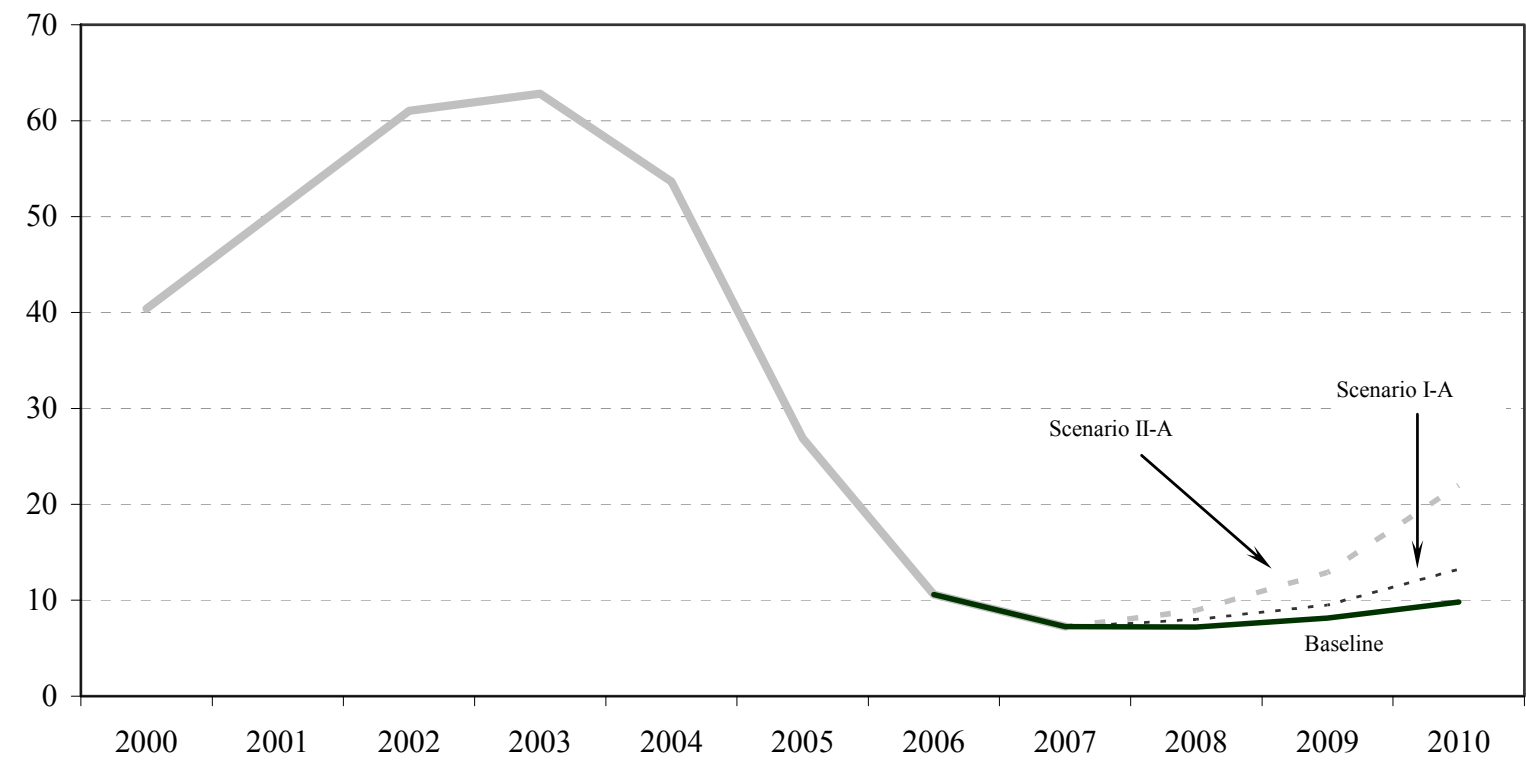

Access model

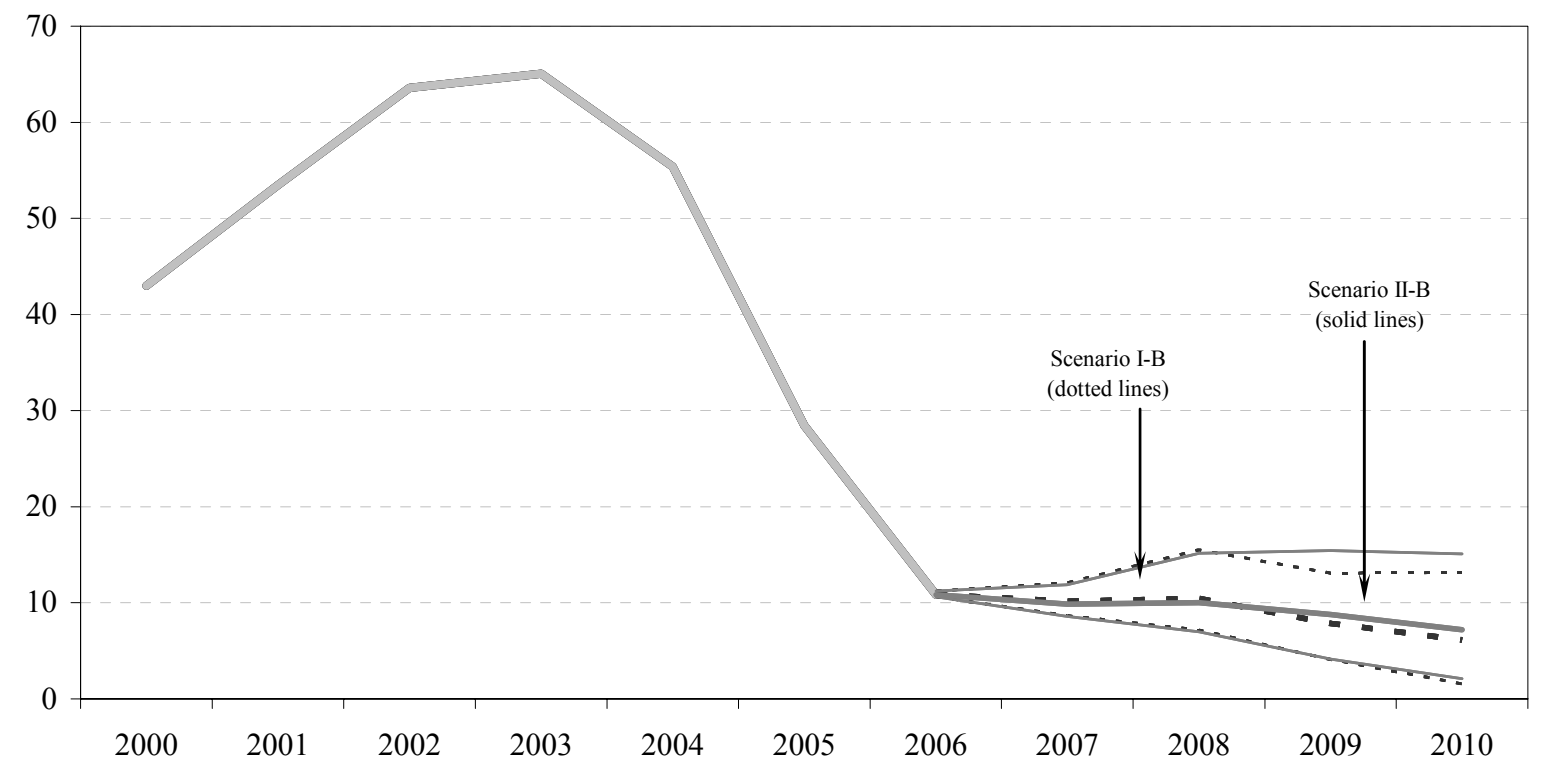

Source: WEO and IMF staff estimates.

1/ Scenario I-A applies 1-year, 3-year, and 5-year ahead forecast errors to the projected WEO debt to GDP ratio. Scenario I-B applies 1-year, 3-year, and 5-year ahead forecast errors to all WEO forecasts for the period 2006-10. Five percent bands added as dotted lines to the access model chart.

2/ Scenario II-A assumes that the increase in the total debt to GDP ratio and the ratio of short-term debt to reserves over the five year period prior to the Asian crisis is repeated in 2007 and 2008 and maintained through 2010. Scenario II-B assumes a two standard deviation shock in oil prices beginning in 2007. 


\section{Conclusions}

This paper presents two approaches to modeling the use of IMF resources in order to gauge whether the recent decline in IMF credit outstanding represents a temporary phenomenon or a permanent shift owing to improved macroeconomic performance and increased resiliency to shocks among middle-income member countries. The two approaches, based respectively on the time series behavior of aggregate IMF credit outstanding and on a two-stage "program selection and access" model, yield the same conclusion: there appears to be a fundamental shift in the use of IMF resources. Specifically, against an average GRA credit outstanding (to middle-income countries) of about SDR 50 billion over the period 2000-05, GRA credit outstanding is projected to average SDR 8 billion over the next five years-with stochastic simulations suggesting that it is unlikely to be much higher.

The projected decline in the aggregate use of IMF resources can be decomposed into two parts: a return to more normal levels of lending given "fundamentals" (i.e., the explanatory variables in the models), and the projected shift in fundamentals. First, the period 2000-05 entailed exceptionally high use of IMF resources, with actual credit outstanding averaging some SDR 50 billion against the predicted level of some SDR 27-40 billion (under the "program selection and access" model and the time series model, respectively). Second, on the basis of projections of the explanatory variables, the predicted level of Fund credit outstanding falls from SDR 27-40 billion in 2000-05 to around SDR 8 billion (under either model) over the period 2006-10. Moreover, these projections assume a stable relationship between fundamentals and use of Fund resources. To the extent that there has been a shift in members' preferences away from seeking the Fund's support - and this shift has not been manifested in improved macroeconomic performance and resilience to shocks-aggregate use of IMF resources could be even lower.

There are, however, important methodological caveats to the analysis. In particular, forecasts of UFR are conditional on the underlying forecasts of macroeconomic performance of middle-income countries (especially dynamics of external debt and reserves). To the extent that projections of economic performance reflect a continuation of the present exceptionally benign global economic conditions, it is natural to expect that the use of IMF resources will remain at the currently low levels. To assess the robustness of the results, their sensitivity to alternative assumptions is examined using scenario analysis. For example, if current WEO projections turn out to have the same degree of over optimism as in the past, then use of IMF credit would be projected to average SDR 9.5 billion over the next five years.

More generally, it is of course possible that a confluence of unexpected adverse factors will trigger future balance of payments needs, perhaps in several countries simultaneously due to contagion. Nevertheless, the analysis presented here, while preliminary, suggests that use of IMF resources over the next few years is likely to be considerably lower than in the recent past. 


\section{Appendix I. Is there evidence of a nonlinear process in the demand for use of IMF resources?}

As noted in the main text, the time series model assumes a single stochastic process driving the use of IMF resources over the past twenty-five years. Yet, the structure of the portfolio has evolved over time and there are clearly periods - such as the early 1980s and the mid1990 s — when there was more intense lending activity.

This appendix therefore considers whether aggregate UFR can be better described by multiple processes, and what determines the transition across process. For this purpose, Markov switching models, as developed in the economics literature by Hamilton (1989) and Filardo and Gordon (1998) are a useful tool as they can identify discontinuities in the datagenerating process, by modelling of permanent regime changes due to structural shifts as well as extraordinary short-period events. ${ }^{40}$ Moreover, in contrast to simple event studies, the endogenous selection mechanism obviates the need for any a priori identification of the regime or the timing of switches across regimes.

A simple multivariate specification, with a state-dependent shift in mean and two states - a low-lending regime and a high-lending regime - is adopted. ${ }^{41}$ The use of a time-varying transition probability allows the model to incorporate economic variables in determining when a regime switch occurs; the variable used here is an exchange market pressure (EMP) index. The model equations are:

$$
\begin{aligned}
& \mathrm{UFR}_{\mathrm{t}}=\alpha_{0}+\alpha_{1} \mathrm{~S}_{\mathrm{t}}+\beta^{\prime} \mathrm{x}_{\mathrm{t}}+\varepsilon_{\mathrm{t}}, \quad \varepsilon_{\mathrm{t}} \sim \mathrm{N}\left(0, \sigma^{2}\right), \\
& \operatorname{Pr}\left\{\mathrm{S}_{\mathrm{t}}=1\right\}=\operatorname{Pr}\left\{\mathrm{S}_{t}^{*} \geq 0\right\}, \\
& \mathrm{S}_{t}^{*}=\gamma_{0}+\gamma_{1} \mathrm{~S}_{\mathrm{t}-1}+\delta^{\prime} \mathrm{EMP}_{\mathrm{t}-1}+u_{\mathrm{t}}
\end{aligned}
$$

The use of IMF resources is modeled in the measurement equation. The transition probability is estimated by means of a probit model, where the latent variable $\mathrm{S}^{*}$ depends on the previous state but also on lagged values of the EMP index.

The country sample is the same as that used in the main text, but a longer time series and quarterly data is used. For the purpose of the analysis, we use aggregate cross-country time series at quarterly frequency over the period 1974-2005. The EMP index is defined as the average of changes in the nominal exchange rate, in the short term interest rate and in the international ratio of reserves to broad money, weighted by the variable respective volatility

\footnotetext{
${ }^{40}$ See Goretti (2005) for an application of endogenous Markov-switching model to Brazil in 2002.

${ }^{41}$ The test for non-linearity in UFR follows the non-parametric test developed by Luukkonen et al. (1988) and Teräsvirta (1994). The test is a Lagrange Multiplier test for a third-order Taylor approximation to the univariate regression and allows to identify general nonlinearity through the significance of the higher-order terms. The main advantage of this type of test is that it can be carried out by simple OLS and that is sensitive to a wide range of non-linearities. The results of this test are reported in Table 1 and show significant evidence of nonlinearity in the series.
} 
and benchmarked to the US economy. Cross-country aggregation is obtained by weighting each country EMP index by its GDP weight in the sample group.

Appendix Table 1. Determinants of Use of IMF Resources Under Switching Regimes

\begin{tabular}{|c|c|c|c|c|c|}
\hline \multicolumn{3}{|l|}{ Measurement equation: } & \multicolumn{3}{|c|}{ Transition equation: } \\
\hline $\begin{array}{l}\text { Dependent variable: Access amount as } \\
\% \text { of GDP }\end{array}$ & Coefficient & \multicolumn{2}{|l|}{ SE } & Coefficient & SE \\
\hline $\mathrm{a} 0$ & $-9.28^{*}$ & 5.035 & g0 & $-1.60^{* * *}$ & 0.037 \\
\hline a1 & $43.02^{* * *}$ & 5.062 & EMP_1 & $0.41^{* * *}$ & 0.081 \\
\hline (Change in ca/GDP)_1 & $-291.92^{* * *}$ & 71.135 & s_1 & $2.50^{\star * *}$ & 0.168 \\
\hline $\begin{array}{l}\text { Corporate bond premium minus } \\
\text { Fund's rate of charge _ } 1\end{array}$ & $1.15^{\star \star \star}$ & 0.348 & & & \\
\hline Term structure_1 & -0.89 & 0.749 & & & \\
\hline (Total external debt/GDP)_1 & $101.53^{* * *}$ & 19.216 & & & \\
\hline Reserve Coverage_1 & $-7.29^{* * *}$ & 2.459 & & & \\
\hline \multicolumn{6}{|l|}{ Number of observations: 127} \\
\hline$R^{\wedge} 2: 0.588$ & & \multicolumn{4}{|c|}{ Adjusted R^2: 0.552} \\
\hline \multicolumn{2}{|l|}{ Terasvirta Linearity Test for UFR (delay=1): } & \multicolumn{4}{|c|}{$F(3,134)=14.990$ with Sign. Level 0.001} \\
\hline Linear Model Fit $(\mathrm{a} 0=\mathrm{a} 1)$ : & & $R^{\wedge} 2: 0.284$ & Adju & .240 & \\
\hline
\end{tabular}

Note: ${ }^{* * *}$ significant at $1 \%$; ${ }^{* *}$ significant at 5 percent; and * significant at 10 percent

Estimates for the final specification of equation 1 suggest two significantly different states, characterized by an high and low-lending regime (Appendix Table 1). In particular, under the high lending regime, use of IMF resources by this group of countries is almost 34 percent of GDP higher than in the low lending state. In the measurement equation, use of IMF credit (in percent of GDP) is found to depend significantly and with a negative sign on changes in the current account balance, and the corporate bond premium net of IMF's rate of charge. ${ }^{42}$ Total external debt enters into the equation with a significant positive sign. Finally, the EMP index enters directly into the transition equation, proving a significant positive effect on the regime latent variable, which underlines the evident link between crisis probability and access to IMF lending, and the proportionality between the extent of market pressure and the need for exceptional lending programs.

\footnotetext{
${ }^{42}$ Note that the negative sign for the reserve coverage regressor (which already excludes China), although significant, may reflect the almost exponential upward trend in aggregate reserves for this group of countries; in all likelihood this reflects large reserve accumulation in other Asian countries.
} 
The $\mathrm{R}^{2}$ for the regression indicates that the selected explanatory variables account for almost 60 percent of the variation in aggregate IMF credit outstanding. Although the explanatory power of the Markov Switching specification could be further improved, it does outperform the estimates of a simple time series model, as illustrated in Figure 1. Fitted values from the simple (linear) time series model tend to average out the high lending and low lending processes, failing to capture the evident nonlinearity in the data. The nonlinear model is able to identify the main regime shifts in the series. In particular, the smooth probability of IMF high-lending regime recognizes the peaks in the use of IMF resources during the major crisis episodes over the sample period (Figure 2).

Figure 1. Demand for Use of Fund Resources Over Total GDP: Actual versus Fitted Data

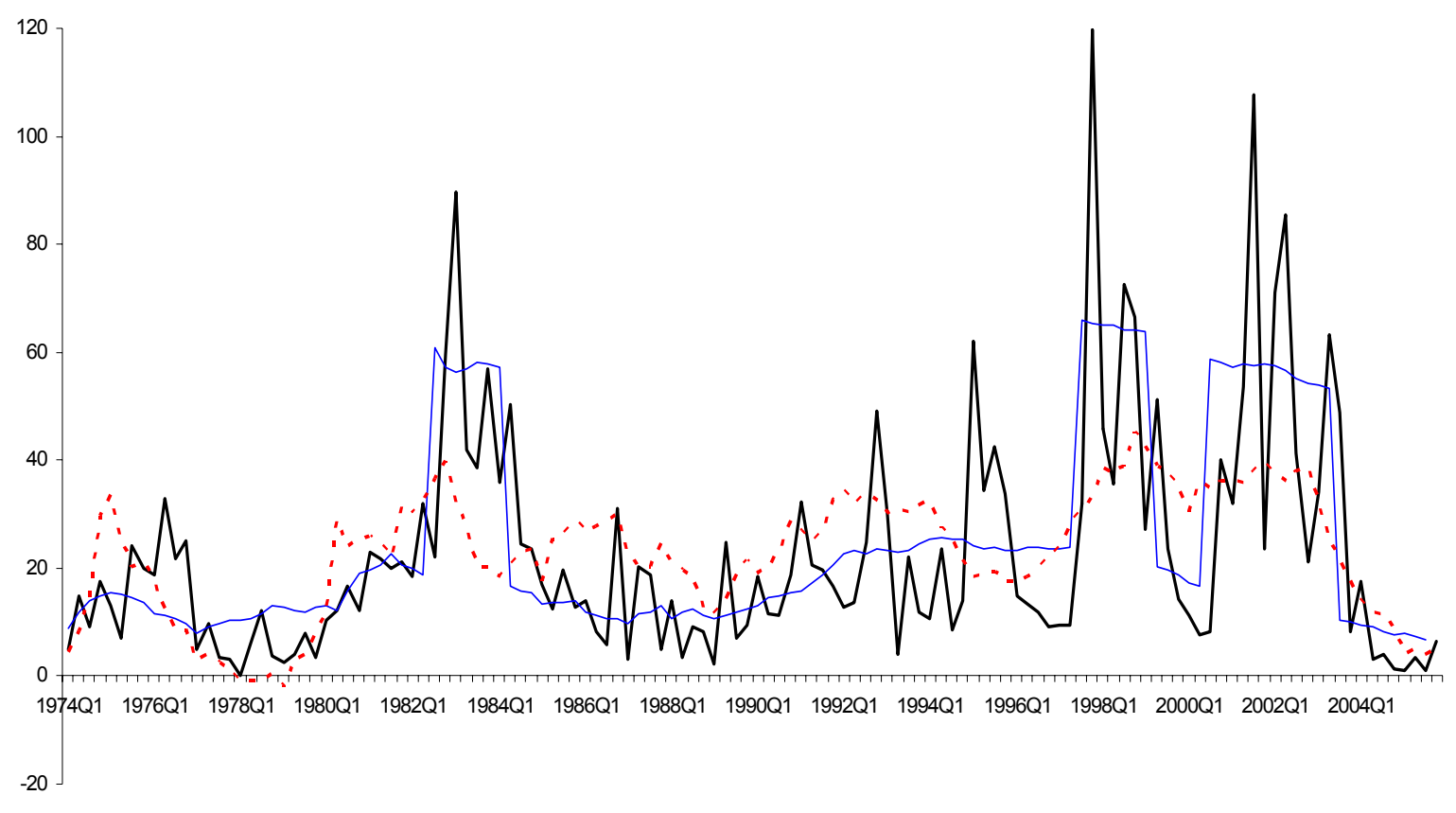

—actual __ Fitted values with MS model $\left(R^{\wedge} 2=0.588\right)=\ldots$. Fitted values with linear model $\left(R^{\wedge} 2=0.284\right)$

These results suggest caution in using only simple linear time series methods - though the Markov switching model of the type used here is of limited use in projecting future use of IMF resources because it is difficult to forecast which state - high or low-lending —will prevail. ${ }^{43}$ For this reason, the main text uses a simple linear time series model — but supplements this analysis with a two-stage program selection logit and access regression.

\footnotetext{
${ }^{43}$ This model does provide probabilities of each state being realized (depicted in the bottom panel of the Figure). A specification that disaggregates UFR into regional components suggests that Asian countries are less likely to be in the high-lending state than Latin American countries. Historically, the only period in the sample where the Asian economies had a high probability of being in the high UFR state was in the mid-1990s.
} 
Figure 2. Use of Fund Credit: Smooth Probability of Fund High-Lending Regime

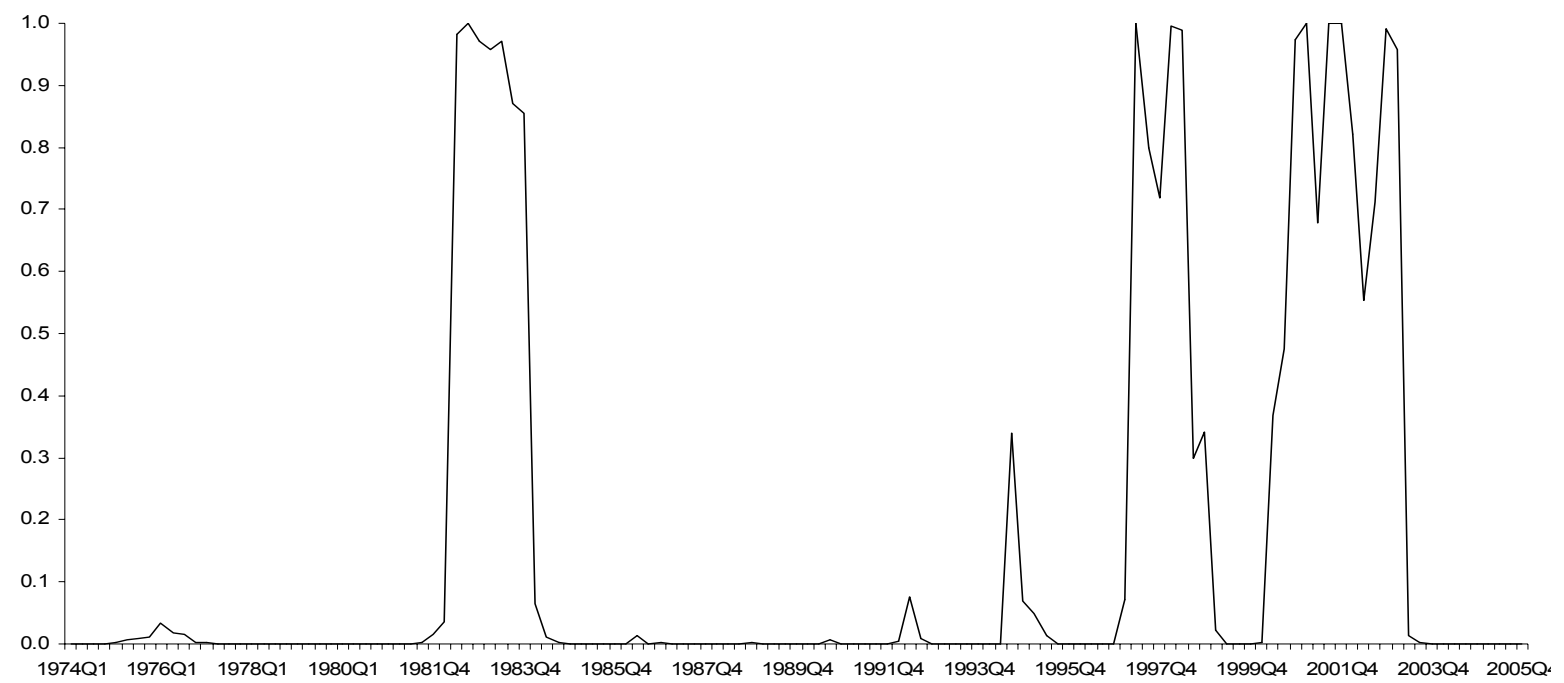




\title{
Appendix II. Demand for IMF Resources-Literature Survey ${ }^{44}$
}

\begin{abstract}
Although the literature on aggregate use of IMF resources is nascent, there are a number of studies that study the economic and political determinants of a member having an IMF-supported program (see Appendix Table 2). Most studies examine a large number of economic and political variables in the context of various econometric models, including limited dependent variable models and OLS regressions on both pooled and panel data. ${ }^{45} \mathrm{~A}$ few papers use case studies or descriptive statistics to try to draw conclusions about the factors leading to demand for IMF credit. The results of the range of studies show, however, that only a few variables consistently emerge as statistically significant. Moreover, while some studies identify factors that increase the probability of a member country requesting an IMF-supported program, they are less successful at predicting actual access levels owing in part to the increasing importance of capital account crises in outstanding IMF credit positions. Since capital account crises are rare events with many different triggers, it is difficult to identify empirical regularities.
\end{abstract}

\section{Global Factors}

- Only a minority of studies included global environment factors. These included real or nominal industrial country interest rates, global GDP growth, commodity prices, ${ }^{46}$ or total outstanding IMF credit (generally interpreted as a measure of the IMF's budget constraint) among the explanatory variables, with mixed results.

\section{Country-Specific Factors}

- Economic variables: Many studies find the level of reserves, generally measured by their coverage of imports, ${ }^{47}$ and the level of economic development of a country (measured by GNP per capita) to be negatively correlated with use of IMF credit at

\footnotetext{
${ }^{44}$ This appendix is an abbreviated version of a survey prepared by Patricia Brukoff, Julie Kozack, Alex Pitt, and Björn Rother.

${ }^{45}$ The OLS regressions use various measures of the demand for Fund credit, including new gross and net purchases (in millions of SDRs or as a share of GDP).

${ }^{46}$ Elekdağ (2005) examines the effect of oil prices on the demand for IMF credit. That study finds a positive and significant relationship between oil prices and the probability of an IMF-supported program being approved. Joshi and Zalduendo (2006) extend the framework put forward by Elekdağ by using a two stage procedure that enables to estimate country access after controlling for a country's decision to request a program. Specifically, the paper identifies factors that influence the decision to request a stand-by arrangement and, given that decision, examines the factors that determine program access levels. This paper also restricts the sample to SBA-type only programs, thus addressing another of the methodological problems found in the literature. Nevertheless, given the rare event nature of recent capital account crises cases, the model underpredicts actual demand for Fund resources frequently during the 1990s.

${ }^{47}$ There is evidence that the level of reserves may be a relevant factor only where the exchange rate is fixed.
} 
conventional significance levels. ${ }^{48}$ Several studies also find - though not always consistently - the current account and/or overall balance of payments position; GDP growth; external debt service; external debt; access to private financing; real exchange rate overvaluation; investment levels; and measures of public expenditure or fiscal deficits significant.

- "Political" variables: Among the "political" variables, a previous IMF arrangement is a powerful predictor of future IMF arrangements in some circumstances (the authors generally interpret a previous program as carrying a fixed political cost associated with a close relationship to the IMF, which, once incurred, makes governments less reluctant to request further IMF assistance). Some studies also identify political or economic alignment with the United States and the time until the next election as a factor.

\section{Drawbacks of the Studies}

The usefulness of these studies to help assess the future demand for IMF credit is limited, for a variety of reasons. First, the predictive power of the models appears to be very poor. Second, most of the studies do not cover the financial crises of the 1990s. Third, methodological and data frequency issues suggest that it is very difficult to estimate the demand for IMF credit with a reasonable degree of accuracy.

- In most studies, the prediction accuracy is only marginally better than the naïve prediction of always forecasting no program. Specifically, while the various models correctly project 80-90 percent of total outcomes in in-sample forecasts of the demand of IMF credit, a simple guess of "no agreement" would typically be accurate about 80 percent of the time (see Bird and Rowlands 2001). Out-of-sample forecasts are included only in three of the studies: (i) Bird (1995) found that his model could not be used for forecasting, and that studies based solely on country economic characteristics tended to overestimate the number of countries that will borrow from the IMF; (ii) in contrast, preliminary results by Elekdağ (2005), using a comprehensive sample, indicate a projected number of five to six new stand-by approvals in 2004, compared to an actual realization of six; and (iii) Joshi and Zalduendo (2006) find that the model has limited success in predicting access levels in the context of capital account crises, suggesting that these rare events are a source of uncertainty that needs to be understood better.

- Most of the studies do not cover the second half of the 1990s and are therefore likely to miss important vulnerabilities associated with stock imbalances emerging in capital account crises. ${ }^{49}$ Furthermore, of those studies that do cover this period, several do not

\footnotetext{
${ }^{48}$ Only two studies (Marchesi (2002) and Bird (1995)) did not find reserves to be significant in their econometric models. Vreeland (2004), Marchesi (2002), Bird and Rowlands (2001), Thacker (1999), Santaella (1996) did not find the level of economic development significant. Several other studies did not include a proxy for the level of economic development.

${ }^{49}$ Only Barro and Lee (2002), Bird and Rowlands, Elekdağ (2005), Joshi and Zalduendo (2006), Sturm et al. (2005), and Trudel (2005) cover the period through at least the year 2000.
} 
adjust their choice of economic variables to account for the fact that balance of payments needs in this period originated in the capital account, using for instance, the reserves-toimports ratio rather than the ratio of reserves to M2 or short-term debt, which the literature on early warning systems has shown to be more closely related to the break of capital account crises than the more traditional indicator. ${ }^{50}$ Moreover, one of the more recent studies (Oatley and Yackee 2000) uses dummy variables to account for the Asian and/or Russian crises, giving rise to a trivial association of the demand for IMF credit with the existence of financial crises, which is of no help in an exercise aimed at forecasting future demand.

- In all but three of the studies surveyed, the analysis does not distinguish between the various types of IMF facilities. In most studies, the analysis is based on data for all types of IMF arrangements, even though the determinants of demand for IMF credit under a stand-by arrangement (SBA) are likely to be quite different from those associated with longer-term facilities, including concessional ones. This intermingling of demand for IMF credit under the various facilities would make it difficult to use the results of these models to forecast future demand for IMF credit under the GRA alone.

- Only four out of the 20 studies use the amount of IMF credit as dependent variable. ${ }^{51}$ Most studies estimate the probability of approval of an arrangement in a limited dependent variable model. It is not clear that the two variables should be determined by the same set of explanatory factors. While the probability of approval of an arrangement should be influenced by macroeconomic, structural, and political variables, the amounts of IMF credit should be a function of the agreed-upon policy response to a crisis.

- Related to this, the low frequency of the data used in all studies may create additional problems for projecting demand for IMF resources in financial crises. In these crises, balance sheet pressures tend to build quickly, and sometimes over much shorter horizons than 12 months, driven by sudden changes in investor sentiment and portfolio allocation. More broadly, the use of annual data makes it hard to distinguish between economic and political conditions prior to and after approval of a IMF arrangement (when corrective policies start to be implemented).

\footnotetext{
${ }^{50}$ For an overview of this literature, see Berg, Borensztein, and Patillo (2004).

${ }^{51}$ Barro and Lee (2005), Bird (1995), Oatley and Yackee (2000), and Dreher and Vaubel (2001).
} 


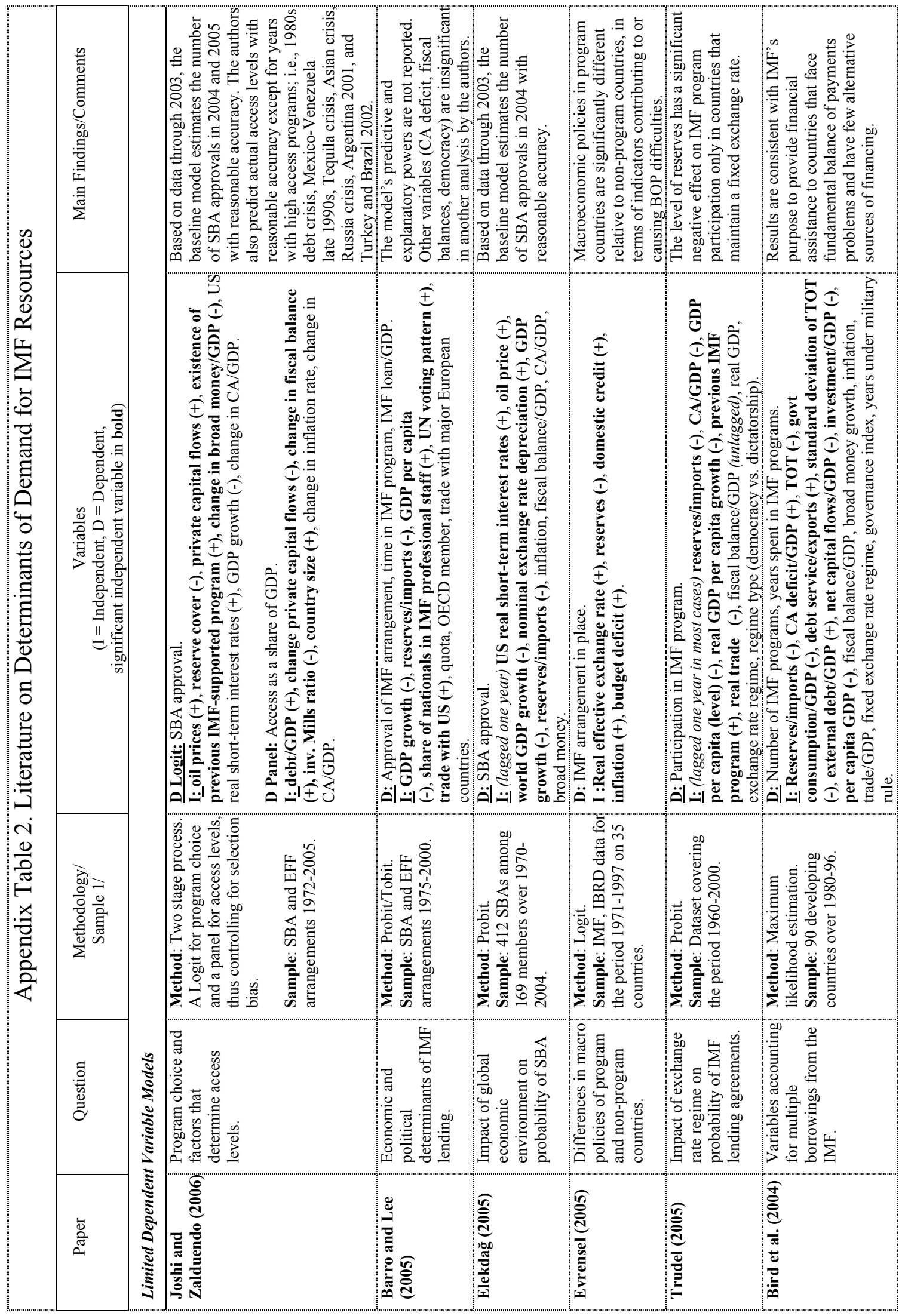




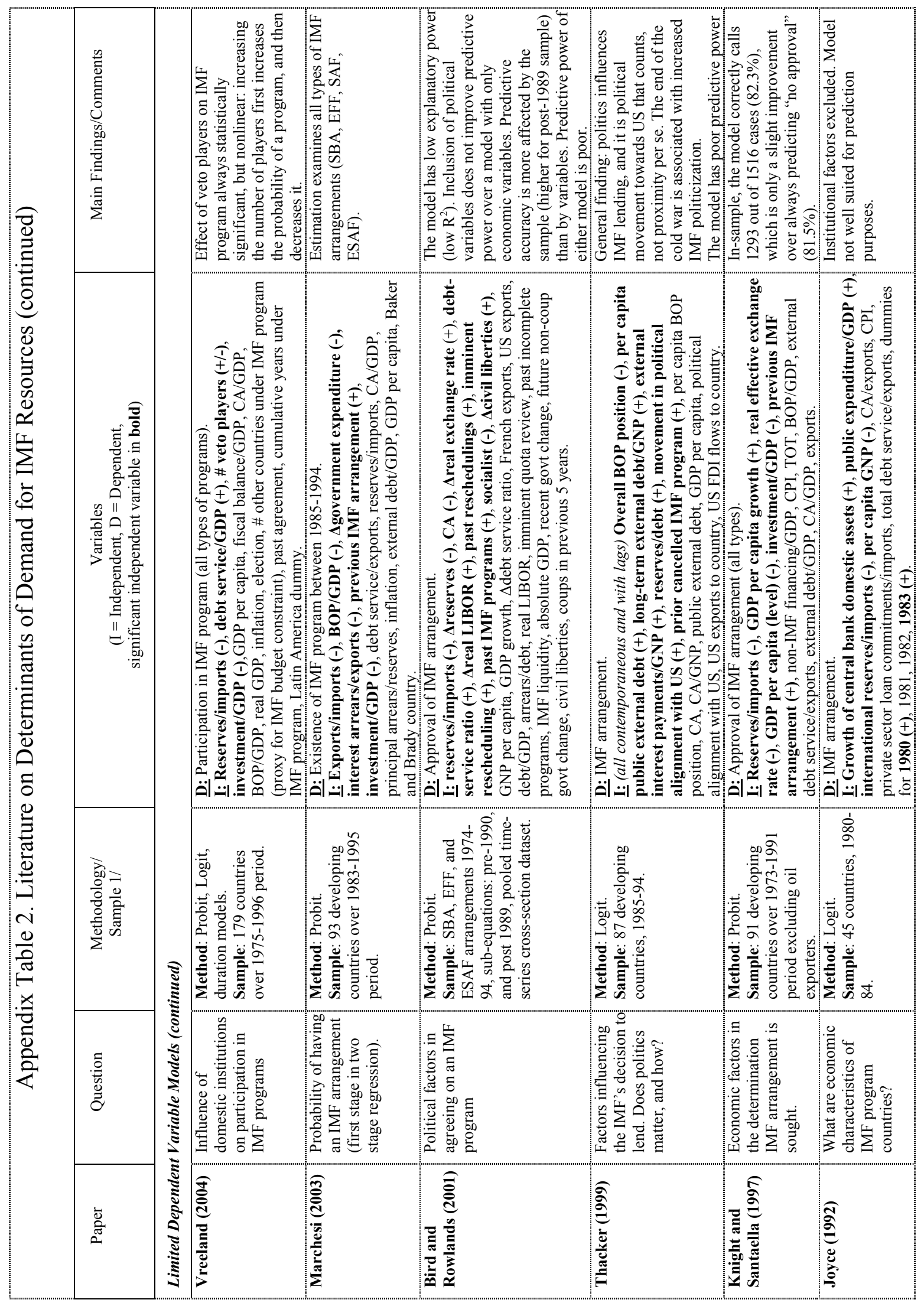




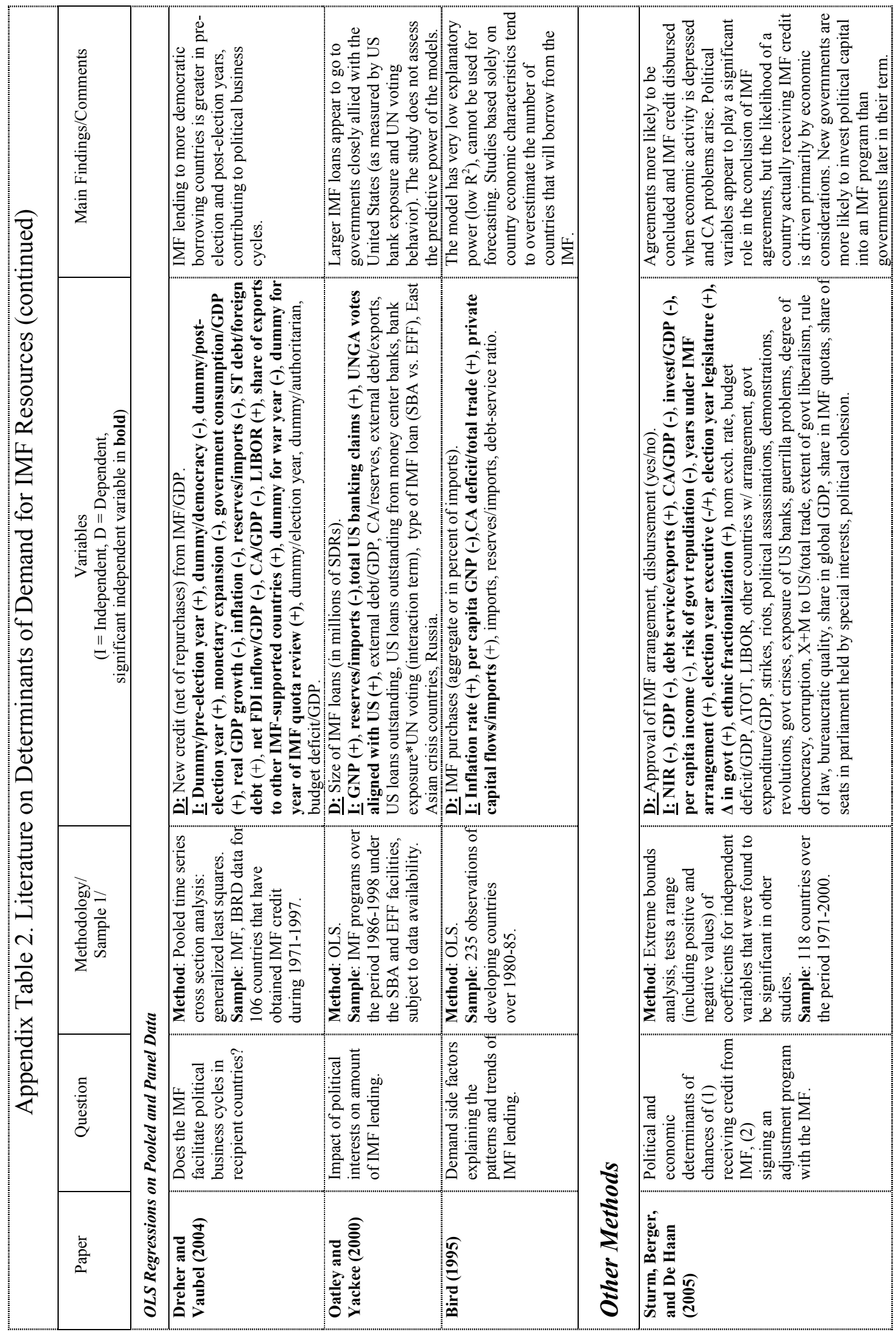




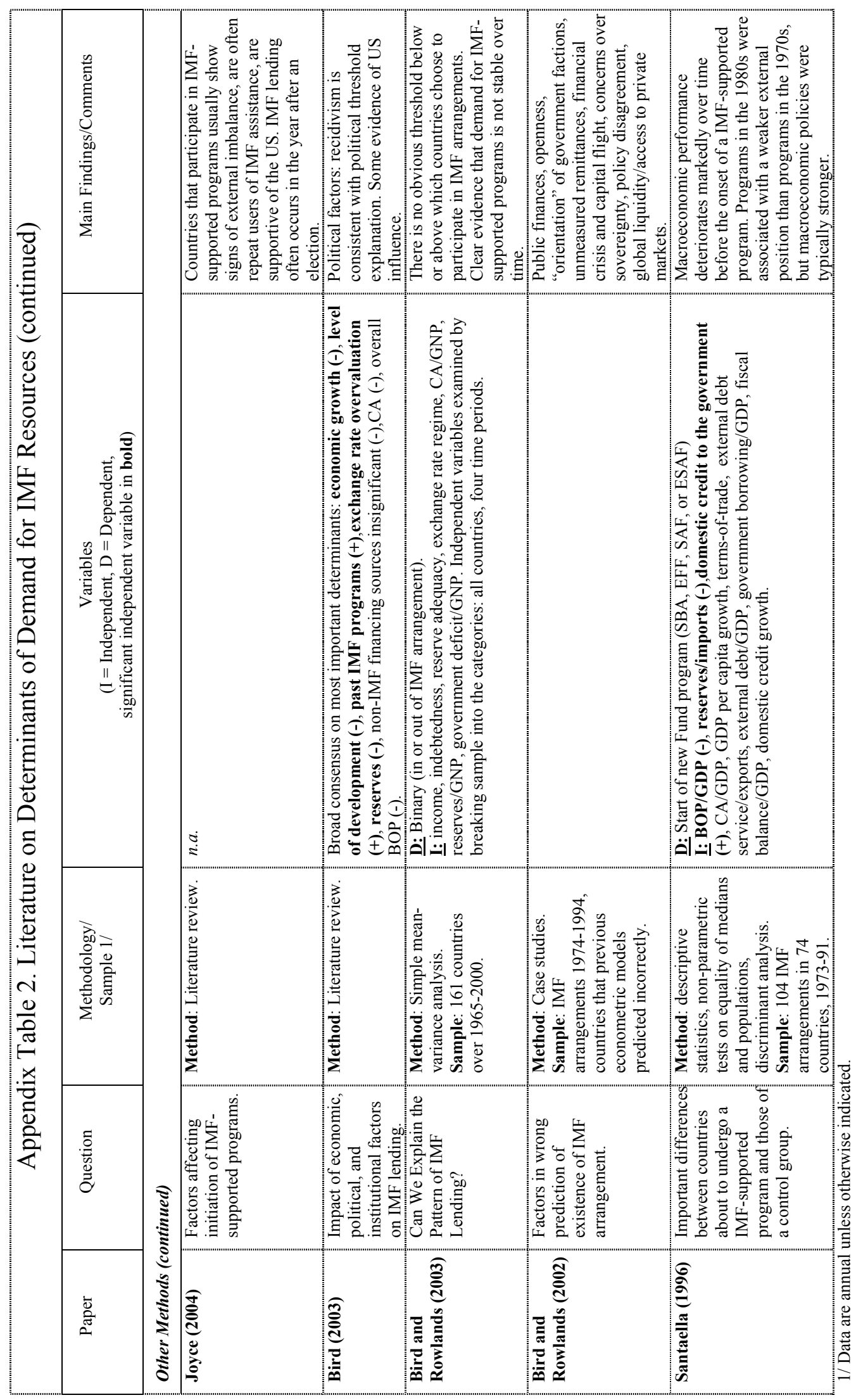




\section{References}

Barro, Robert and Jong-Wha Lee, 2005, "IMF Programs: Who is Chosen and What Are the Effects?” Journal of Monetary Economics, Vol. 52, no. 7, (October), pp. 1245-69.

Berg, Andrew, Eduardo Borensztein, and Catherine Pattillo, 2004, "Assessing Early Warning Systems: How Have They Worked in Practice?” IMF Working Paper No. 04/52 (Washington: International Monetary Fund).

Bird, Graham, 1995, IMF Lending to Developing Countries: Issues and Evidence (London; New York: Routledge).

,2003, The IMF and the Future: Issues and Options Facing the Fund (London; New York: Routledge).

Bird, Graham and Dane Rowlands, 2001, "IMF Lending: How Is It Affected by Economic, Political and Institutional Factors?" Journal of Policy Reform, Vol. 4, No. 3, pp. 24370 . , 2002, "The Pattern of IMF Lending: An Analysis of Prediction Failures," Journal of Policy Reform, Vol. 5, No. 3, (September), pp. 173-86.

, 2003, “Can We Explain the Pattern of IMF Lending?” mimeo.

Bird, Graham, Mumtaz Hussain, and Joseph P. Joyce, 2004, "Many Happy Returns?

Recidivism and the IMF," Journal of International Money and Finance, Vol. 23, No. 2 (March) pp. 231-51.

Brukoff, Patricia, Julie Kozack, Alex Pitt, and Björn Rother, 2006, "Demand for IMF Resources, A Literature Survey," mimeo.

Cerutti, Eugenio, 2007, “IMF Drawing Programs: Participation Determinants and Forecasting", forthcoming.

Dolton, Peter, and Gerald Makepeace, 1987, "Interpreting Sample Selection Effects," Economics Letters, Vol. 24, pp. 373-379.

Dreher, Axel and Roland Vaubel, 2004, "Do IMF and IBRD Cause Moral Hazard and Political Business Cycles? Evidence from Panel Data," Open Economies Review, Vol. 15, No. 1 (January), pp. 5-22.

Dubin, Jeffrey and Daniel McFadden, 1984, “An Econometric Analysis of Residential Appliaance Holdings and Consumption," Econometrica, Vol. 52, No. 2, pp. 345-362. 
Elekdağ, Selim 2006, "How Does the Global Economic Environment Influence the Demand for IMF Resource?” IMF Working Paper No. 06/239 (Washington: International Monetary Fund).

Estrella, Arturo, 1998, “A New Measure of Fit for Equations with Dichotomous Dependent Variables," Journal of Business and Economic Statistics, Vol. 16, No. 2, pp. 198-205.

Evrensel, Ayse, 2005, “IMF Programmes in Emerging Countries," Comparative Economic Studies, Vol. 47, pp 4-22.

Filardo, Andrew and Stephen Gordon, 1998, "Business Cycle Durations," Journal of Econometrics, Vol. 85, pp. 99-123.

Ghosh, Atish, Charis Christofides, Jun Kim, Laura Papi, Uma Ramakrishnan, Alun Thomas, and Juan Zalduendo, 2005, The Design of IMF-Supported Programs, IMF Occasional Paper No. 241 (Washington: International Monetary Fund).

Goretti, Manuela, 2005, “The Brazilian Currency Turmoil of 2002: A Nonlinear Analysis," International Journal of Finance \& Economics, Vol. 10, No. 4, pp. 289-306.

Hamilton, James, 1989, "A New Approach to the Economic Analysis of Nonstationary Time Series and the Business Cycle," Econometrica, Vol. 57, No. 2, pp. 357-384.

Heckman, James, 1979, "Sample Selection Bias as a Specification Error,” Econometrica, Vol. 47, No. 1, pp. 153-162.

Horsefield, J. Keith, 1969, The International Monetary Fund, 1945-1965-Twenty Years of International Monetary Cooperation (Washington: International Monetary Fund).

IMF, 2000, "Review of Fund Facilities_-Proposed Decisions and Implementation Guidelines," (Washington: International Monetary Fund), available at http://www.imf.org/external/np/pdr/fac/2000/02/index.htm.

, 2002a, "Assessing Sustainability," (Washington: International Monetary Fund), available at http://www.imf.org/external/np/pdr/sus/2002/eng/052802.pdf.

,2002b, “Access Policy in Capital Account Crises," (Washington: International Monetary Fund), available at http://www.imf.org/external/np/tre/access/2003/pdf/072902.pdf.

,2003, "Access Policy in Capital Account Crises-Modifications to the Supplemental Reserve Facility (SRF) and Follow-up Issues Related to Exceptional Access Policy," (Washington: International Monetary Fund), available at http://www.imf.org/external/np/tre/access/2003/pdf/011403.pdf. 
, 2005a, "Are Fund Staff Projections of Debt More Optimistic Under Program Contexts?" (Washington: International Monetary Fund), available at http://www.imf.org/external/np/pp/eng/2005/110905.pdf.

,2005b, Selected Decisions and Selected Documents of the International Monetary Fund (Washington: International Monetary Fund).

, 2006, "Precautionary Arrangements: Purposes and Performance," (Washington: International Monetary Fund), available at http://www.imf.org/external/np/pp/eng/2006/032306p.pdf.

Joshi, Bikas and Atish Ghosh, 2003, "How Good (or Bad) Are Fund Projections?" (Unpublished; Washington: International Monetary Fund).

Joshi, Bikas and Juan Zalduendo, 2006, "A Note on Program Selection and Access Levels," unpublished (Washington: International Monetary Fund).

Joyce, Joseph, 1992, "The Economic Characteristics of IMF Program Countries," Economics Letters, Vol. 38, No. 2 (February), pp. 237-42.

, 2004, "Adoption, Implementation, and Impact of IMF Programmes: A Review of the Issues and Evidence," Comparative Economic Studies, 46, pp. 451-67.

Knight, Malcolm and Julio Santaella, 1997, "Economic Determinants of Fund Financial Arrangements," Journal of Development Economics, Vol. 54, pp 405-36.

Luukkonen, Ritva, Pentti Saikkonen, and Timo Teräsvirta, 1988, "Testing Linearity against Smooth Transition Autoregressive Models," Biometrika, Vol. 75, pp. 491-499.

Maddala, G., 1983, Limited Dependent and Qualitative Variables in Economics, Econometric Society Monographs (Cambridge: Cambridge University Press).

Marchesi, Silvia, 2003, “Adoption of an IMF Programme and Debt Rescheduling: An Empirical Analysis,” Journal of Development Economics, Vol. 70, No. 2 (April), pp. 403-23.

Oatley, Thomas and Jackson Yackee, 2000, "Political Determinants of IMF Balance of Payments Lending: The Curse of Carabosse?" mimeo (University of North Carolina).

Phillips, Peter, 1986, "Understanding Spurious Regressions in Econometrics," Journal of Econometrics, Vol. 33, pp. 311-340.

Poirier, Dale, 1980, "Partial Observability in Bivariate Probit Models," Journal of Econometrics, Vol. 12, pp. 209-17. 
Przeworski, Adam and James Vreeland, 2000, "The Effect of IMF Programs on Economic Growth,” Journal of Development Economics, Vol. 62, pp. 385-421.

Royal Swedish Academy of Sciences, 2000, "The Scientific Contributions of James Heckman and Daniel McFadden," available at http://nobelprize.org/nobel_prizes/economics/laureates/2000/ecoadv.pdf.

Santaella, Julio, 1996, "Stylized Facts Before IMF-Supported Macroeconomic Adjustment," IMF Staff Papers, Vol. 43, No. 3 (Sept).

Sturm, Jan-Egbert, Helge Berger, and Jakob de Haan, 2005, "Which Variables Explain Decisions on IMF Credit? An Extreme Bounds Analysis," Economics and Politics, Vol. 17, No. 2 (July), pp. 177-213.

Teräsvirta, Timo, 1994, "Specification, Estimation, and Evaluation of Smooth Transition Autoregressive Models," Journal of the American Statistical Association, Vol. 89, pp. 208-218.

Thacker, Strom, 1999, “The High Politics of IMF Lending," World Politics, 52, No. 1.

Train, Kenneth, 2003, Discrete Choice Methods with Simulation, Cambridge University Press.

Trudel, Robert, 2005, "Effects of Exchange Rate Regime on IMF Program Participation," Review of Policy Research, Vol. 22, No. 6.

Vreeland, James, 2004, "Institutional Determinants of IMF Agreements," Global Fellows Working Paper (Los Angeles: University of California).

Windmeijer, Frank, 1995, "Goodness-of-Fit Measures in Binary Choice Models," Econometric Reviews, Vol. 14, No. 1, pp. 101-116. 